\title{
Selective activation of estrogen receptors $\alpha$ and $\beta$ : Implications for depressive-like phenotypes in female mice exposed to chronic unpredictable stress
}

Rand S. Eid ${ }^{1,3}$, Stephanie E. Lieblich ${ }^{2,3}$, Paula Duarte-Guterman ${ }^{2,3}$, Jessica A. Chaiton ${ }^{2,3}$, Amanda G. $\mathrm{Mah}^{3}$, Sarah J. Wong ${ }^{2,3}$, Yanhua Wen ${ }^{2,3}$, and Liisa A.M. Galea ${ }^{1,2,3}$

${ }^{1}$ Graduate program in Neuroscience, University of British Columbia, Vancouver, BC

${ }^{2}$ Department of Psychology, University of British Columbia, Vancouver, BC

${ }^{3}$ Djavad Mowafaghian Centre for Brain Health, University of British Columbia, Vancouver, BC

Corresponding author:

Dr. Liisa Galea

Djavad Mowafaghian Centre for Brain Health

University of British Columbia

2215 Wesbrook Mall

Vancouver, BC

Canada, V6T 1 Z3

Tel: $+1(604) 8226536$

Email: liisa.galea@ubc.ca 


\section{Abstract}

The estrogen receptor (ER) mechanisms by which $17 \beta$-estradiol influences depressive-like behaviour have primarily been investigated acutely and not within an animal model of depression. Therefore, the current study aimed to dissect the contribution of $\operatorname{ER} \alpha$ and $\operatorname{ER} \beta$ to the effects of $17 \beta$-estradiol under non-stress and chronic stress conditions. Ovariectomized (OVX) or sham-operated mice were treated chronically (47 days) with 17 $\beta$-estradiol (E2), the ER $\beta$ agonist diarylpropionitrile (DPN), the ER $\alpha$ agonist propylpyrazole-triol (PPT), or vehicle. On day 15 of treatment, mice from each group were assigned to Chronic Unpredictable Stress (CUS; 28 days) or non-CUS conditions. Mice were assessed for anxiety- and depressive-like behaviour and hypothalamic-pituitary-adrenal (HPA) axis function. Cytokine and chemokine levels, and postsynaptic density protein 95 were measured in the hippocampus and frontal cortex, and adult hippocampal neurogenesis was assessed. Overall, the effects of CUS were more robust that those of estrogenic treatments, as seen by increased immobility in the tail suspension test (TST), reduced PSD-95 expression, reduced neurogenesis in the ventral hippocampus, and HPA axis negative feedback dysregulation. However, we also observe CUSdependent and -independent effects of ovarian status and estrogenic treatments. The effects of CUS on PSD-95 expression, the cytokine milieu, and in TST were largely driven by PPT and DPN, indicating that these treatments were not protective. Independent of CUS, estradiol increased neurogenesis in the dorsal hippocampus, blunted the corticosterone response to an acute stressor, but increased anxiety-like behaviour. These findings provide insights into the complexities of estrogen signaling in modulating depressive-like phenotypes under non-stress and chronic stress conditions.

Key words: ovariectomy; $17 \beta$-estradiol; estrogen receptor $\alpha$; estrogen receptor $\beta$; chronic unpredictable stress; hippocampus; frontal cortex; cytokines; neurogenesis; postsynaptic density protein 95 


\section{Introduction}

Major depressive disorder (MDD) is a stress-related psychiatric disorder that affects approximately twice more women than men (Kessler and Bromet, 2013; Salk et al., 2017). Given this disparity in prevalence rates, a focus on female-specific factors that may contribute to depression is warranted. Sex differences in prevalence rates first emerge around puberty (Salk et al., 2017), suggesting that ovarian hormones may increase risk for depression in women. However, periods associated with declines in ovarian hormones, including the postpartum and perimenopause, are associated with a heightened risk for depression in women (Cohen et al., 2006; Hendrick et al., 1998; Soares, 2014), supporting the notion that ovarian hormones may afford resilience, rather than risk. The complex roles of ovarian hormones in depression may be partly attributed to the diversity of estrogen signaling, which can be loosely categorized into genomic and non-genomic mechanisms (Björnström and Sjöberg, 2005).

Evidence from animal models suggests that $17 \beta$-estradiol may interact with classical estrogen receptors (ERs) to regulate affective function. However, this is primarily derived from studies that have used tests of depressive- and anxiety-like behaviour in the absence of any manipulations intended to induce depressive- or anxiety-like phenotypes (e.g. chronic stress). For example, the administration of $17 \beta$-estradiol or an ER $\beta$ but not ER $\alpha$ agonist to ovariectomized rats decreases anxiety- and depressivelike behaviour (Walf et al., 2004; Walf and Frye, 2005; Weiser et al., 2009; Yang et al., 2014). Moreover, the anxiolytic and antidepressant-like effects of $17 \beta$-estradiol are not observed in ER $\beta$ knockout mice (Rocha et al., 2005). Collectively these findings indicate that $17 \beta$-estradiol's effects on affective behaviours may be primarily mediated via interactions with ER $\beta$. Importantly, the effects ER activation in "healthy" animals may not mirror those in animals displaying depressive-like pathology, and as such although informative, these findings are certainly not conclusive. Indeed, a more recent study found that overexpression of $\operatorname{ER} \alpha$ in the nucleus accumbens afforded resilience to the depressivelike outcomes after stress exposure in female mice (Lorsch et al., 2018), but the authors did not test the effects of ER $\beta$ overexpression. Thus, to date, the mediatory roles of ER $\alpha$ and ER $\beta$ have not been investigated systematically and within an animal model of depression. The current study therefore utilized the chronic unpredictable stress (CUS) model in female mice with the aim of dissecting the contribution of ER $\alpha$ and $\operatorname{ER} \beta$ to the estrogenic modulation of depressive-like pathology.

Endocrine and immune systems engage in extensive crosstalk (Bereshchenko et al., 2018; Grossman, 1985; Olsen and Kovacs, 1996). 17ß-Estradiol in particular possesses immunomodulatory properties that are mediated via interactions with both $\operatorname{ER} \alpha$ and $\operatorname{ER} \beta$ (Baker et al., 2004; Kovats, 2015; 
Saijo et al., 2011). For example, several in vitro and in vivo studies in females reveal the capacity for $17 \beta$-estradiol and selective ER modulators (SERMs) to ameliorate inflammation and microglial activation in response to inflammatory challenges (Baker et al., 2004; Brown et al., 2010; Ishihara et al., 2015; Vegeto et al., 2008, 2001). The anti-inflammatory properties of estradiol may be of particular interest within the context of depression, as inflammation in MDD has been well-documented and corroborated by animal models of stress exposure (Hodes et al., 2015; Miller and Raison, 2016). Indeed, meta-analyses show increased proinflammatory cytokines including IL-6 and TNF- $\alpha$ in blood, cerebrospinal fluid, and brains of individuals with MDD (Dowlati et al., 2010; Enache et al., 2019; Haapakoski et al., 2015). Despite this, there has been insufficient consideration of how sex and sex hormones can influence the association between depression and inflammation (reviewed in Eid et al., $2019 b)$. It is plausible that the immunomodulatory effects of $17 \beta$-estradiol are implicated in depression and the outcomes of stress exposure, yet the receptor mechanisms by which $17 \beta$-estradiol can influence chronic stress-induced inflammation remain unclear.

The hippocampus retains the ability to produce new neurons in adulthood in a variety of species including humans (Kempermann et al., 2018; Moreno-Jiménez et al., 2019; Tobin et al., 2019). Adult hippocampal neurogenesis is reduced by chronic stress, promotes stress resilience, and is implicated in affective function and hypothalamic-pituitary-adrenal (HPA) axis regulation (Anacker et al., 2018; Schoenfeld and Gould, 2012; Surget et al., 2011), although most of this evidence is derived from male rodents. Importantly, 17 $\beta$-estradiol influences adult hippocampal neurogenesis in females (reviewed in Mahmoud et al., 2016b) and its pro-proliferative effects are mediated via actions on both ER $\alpha$ and ER $\beta$, at least acutely (Mazzucco et al., 2006). However, whether chronic activation of ER $\alpha$ and ER $\beta$ influences the survival of newly produced hippocampal neurons under basal or chronic stress conditions has not been investigated. Beyond hippocampal neurogenesis, both estrogens and stress exposure affect synaptic plasticity in a variety of brain regions, including the hippocampus and frontal cortex (Brinton, 2009; Li et al., 2004; McEwen, 2013; McEwen et al., 2016; Srivastava and Penzes, 2011). Estradiol and $\mathrm{ER} \alpha$ or $\beta$ agonist upregulate the expression of synaptic proteins in female rats (Waters et al., 2009), including the postsynaptic density protein 95 (PSD-95), a scaffolding protein which organizes synaptic elements that are important for synaptic function and plasticity (Kim and Sheng, 2004). Importantly, PSD-95 is reduced in the prefrontal cortex (PFC) of individuals with MDD (Feyissa et al., 2009) and in animal models of stress exposure (Kallarackal et al., 2013; Kim and Leem, 2016; Pacheco et al., 2017). Yet, whether and by what receptor mechanisms can $17 \beta$-estradiol influence the effects of stress on PSD-95 remains to be elucidated. 
Dysregulation of the HPA axis is observed in a subset of individuals with MDD, and includes hypercortisolemia, aberrations in the circadian rhythm of cortisol, and impairments in HPA axis negative feedback function (Ising et al., 2007; Stetler and Miller, 2011). Importantly, the HPA axis interacts bidirectionally with the hypothalamic pituitary gonadal (HPG) axis (Reviewed in Goel et al., 2014). HPA-HPG interactions in females have been primarily investigated at baseline or in response to acute stressors; in general, $17 \beta$-estradiol stimulates HPA axis activity and impairs its negative feedback function (Goel et al., 2014), with opposing roles of ER $\alpha$ and $E R \beta$ (Weiser et al., 2010; Weiser and Handa, 2009). Importantly, these effects of $17 \beta$-estradiol may not translate to conditions of chronic stress exposure. Indeed, we have shown that long-term ovarian hormone deprivation in rats increased HPA axis negative feedback impairment under chronic stress exposure (Mahmoud et al., 2016), which parallels findings in MDD indicating greater negative feedback impairment in women post-menopause (Roy et al., 1986; Young et al., 1993). Therefore, we investigated the roles of ER $\alpha$ and ER $\beta$ in mediating the effects of estradiol on HPA axis function under chronic stress conditions.

In this study, we sought to determine whether $17 \beta$-estradiol conferred resilience in the face of CUS in adult female mice. We further employed a pharmacological approach to disentangle the contribution of $\mathrm{ER} \alpha$ and $\mathrm{ER} \beta$ to the effects of $17 \beta$-estradiol under non-stress and chronic stress conditions. We examined stress susceptible behaviours, markers of plasticity in the hippocampus and frontal cortex, central immune mediators, and HPA axis function. We hypothesized that ovariectomy would increase depressive-like endophenotype under non-stress conditions and further exacerbate the depressive-like outcomes of chronic stress exposure. Additionally, we expected estradiol treatment to rescue the effects of ovariectomy and that its actions would be differentially facilitated by $\operatorname{ER} \alpha$ and $\mathrm{ER} \beta$.

\section{Methods}

\section{Animals}

Young adult female C57BL6/J mice (Charles River Laboratories; Quebec, Canada) arrived at our facility at approximately 8 weeks of age. All mice were group housed and given ad libitum access to food and water. Mice were maintained on a 12-hour light/dark cycle (lights on at 7:00am) in temperature- and humidity-controlled colony rooms $\left(21 \square \pm \square 1^{\circ} \mathrm{C}\right.$ and $50 \square \pm \square 10 \%$, respectively). All procedures were conducted in accordance with the ethical guidelines of the Canadian Council on Animal Care and were approved by the Animal Care Committee at the University of British Columbia. 


\section{Surgery}

All mice received bilateral ovariectomy (OVX) or sham surgery at approximately 3 months of age, adapted from our previously described procedure in rats (Barha et al., 2015; Galea et al., 2018). Briefly, surgery was performed through two lateral skin and muscle incisions under isoflurane anesthesia (5\% induction, $1-1.5 \%$ maintenance), with ketamine $(50 \mathrm{mg} / \mathrm{kg}$; intraperitonially (i.p.)), xylazine (5mg/kg; i.p.), bupivacaine (2mg/kg; local), and Lactated Ringer's Solution (10ml/kg; subcutaneously (s.c.)). Mice received a nonsteroidal anti-inflammatory analgesic at the time of surgery, and at 24- and 48hours post-surgery (Anafen; 5mg/kg; s.c.) and recovered for 7-9 days prior to hormone/agonist treatment (see experimental timeline in Fig. 1).

\section{Hormone and agonist treatment}

Ovariectomized mice were randomly assigned to 1 of 4 treatment groups ( $n=26-28$ per group), receiving daily s.c. injections of one of the following: (i) $17 \beta$-estradiol (E2; $0.04 \mathrm{mg} / \mathrm{kg}$ ), (ii) diarylpropionitrile (DPN; $0.1 \mathrm{mg} / \mathrm{kg}$; ER $\beta$-selective agonist), (iii) propylpyrazole-triol (PPT; $0.1 \mathrm{mg} / \mathrm{kg}$; ER $\alpha$-selective agonist), or (iv) vehicle (sesame oil). To control for injections, shamoperated mice $(n=20)$ also received daily s.c. vehicle injections (sesame oil). We therefore obtained the following 5 treatment groups: E2-treated OVX (E2), DPN-treated OVX (DPN), PPT-treated OVX (PPT), oil-treated OVX (OVX), and oil-treated sham-operated mice (Sham). DPN was chosen as it has a 70-fold greater affinity for ER $\beta$ over ER $\alpha$ (Meyers et al., 2001), and PPT was chosen as it has a 410fold greater affinity for ER $\alpha$ over ER $\beta$ (Stauffer et al., 2000). 17 $\beta$-estradiol has an equally high affinity to both $\operatorname{ER} \alpha$ and $\operatorname{ER} \beta$, and its dose was chosen based on previous work and reports showing physiological circulating estradiol concentrations (Ciana et al., 2003; Harburger et al., 2007). Agonist doses were based on reports of behavioural efficacy (Clipperton et al., 2008; Walf et al., 2008). Treatment persisted for 47 days (see Fig. 1), beginning 14 days prior to CUS exposure. The choice to begin treatment prior to CUS was to examine the potentially protective, rather than therapeutic effects of $17 \beta$-estradiol or agonists.

\section{Bromodeoxyuridine administration}

To label dividing progenitor cells and their progeny, 2 injections of bromodeoxyuridine (BrdU; 200mg/kg; i.p; 8 hours apart) were administered to all mice two weeks after hormone treatment had begun, and one day prior to the initiation of CUS (Fig. 1). This timing of BrdU administration was intended for the examination of the effects of CUS on the survival of new neurons, independent of effects on cell proliferation. 


\section{Chronic Unpredictable Stress}

Mice from each treatment group (Sham, OVX, E2, DPN, and PPT) were randomly assigned to chronic unpredictable stress (CUS) or no-CUS conditions, resulting in 10 groups overall ( $\mathrm{n}=10-14)$. CUS consisted of exposure to 13 stressors, applied twice daily in a pseudo-random order for a duration of 4 weeks (Fig. 1). The CUS protocol was adapted from published reports (Kreisel et al., 2014; R. Mahmoud et al., 2016; Wainwright et al., 2016) and stressors used are detailed in Table 1. Chronic unpredictable stress was chosen as it shows face, construct and predictive validity as an animal model of depression (Willner, 2017). Mice in the no-CUS condition were housed in a separate colony room to avoid the transfer of olfactory cues from CUS-exposed mice (Brechbuhl et al., 2013), and left undisturbed with the exception of daily injections and weekly cage changing.

Table 1. Stressors used in the Chronic Unpredictable Stress paradigm.

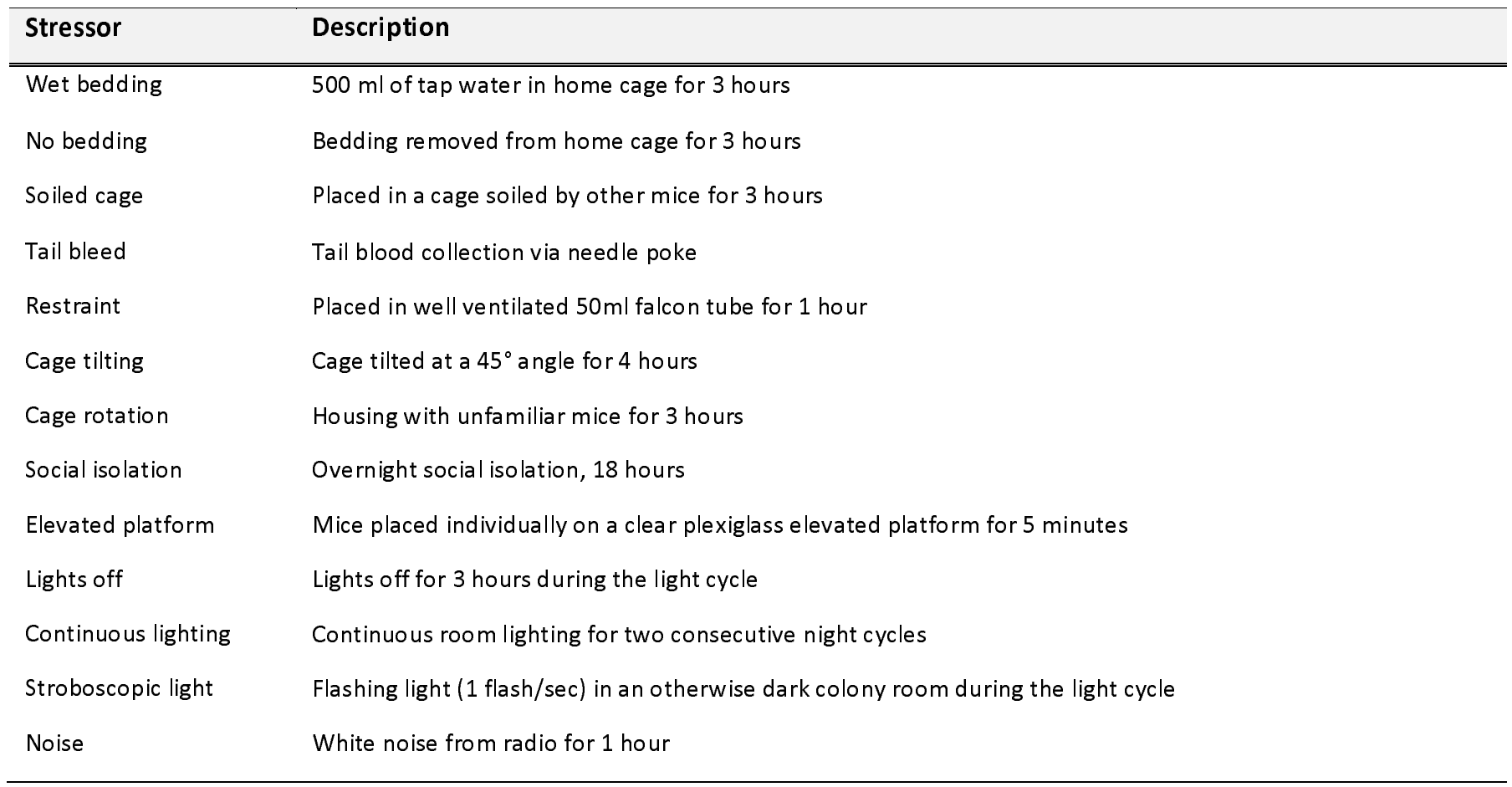

\section{Behavioural Testing}

All mice were assessed on a battery of tests starting the day after CUS. One test was applied per day, and testing occurred in the order depicted in Fig. 1. Mice were acclimatized to testing rooms for 1 hour prior to each test. All behavioural scoring was performed by experimenters blinded to group assignment. 
Forced Swim Test. The forced swim test (FST) was used according to previous methods (Can et al., 2012) to assess stress-coping behaviour which is sensitive to estrogens and exposure to stressors (Monteiro et al., 2015; Rocha et al., 2005). Briefly, under dim light conditions, mice were individually subjected to a 6-minute swimming session in a $4 \mathrm{~L}$ glass beaker containing clean water at $25 \square \pm \square 0.5^{\circ} \mathrm{C}$, filled to a depth of $15 \mathrm{~cm}$. The test was filmed, and time spent in passive-coping behaviour across the test was scored. Mice were considered to display passive-coping behaviour when immobile, with the absence of any movements except those necessary to remain afloat or keep the head above water.

Tail Suspension Test. The tail suspension test (TST) was used as an additional test of stress-coping behaviour, and performed according to standard methods (Can et al., 2011). Briefly, mice were suspended by the tail using laboratory tape (Fisherbrand ${ }^{\mathrm{TM}}$ labeling tape) placed 2-3 $\mathrm{mm}$ from the tip of the tail, in a 3-walled rectangular chamber. Prior to suspension, and to prevent tail-climbing behaviour which is common in this strain, tails were passed through a $4 \mathrm{~cm}$ hollow rubber tubing to cover a portion of the tail, as per previous methods (Can et al., 2011). The 6-minute duration of the test was filmed, and percent time spent immobile was considered an index of passive-coping behaviour.

Sucrose preference test. Anhedonia-like behaviour was assessed in the sucrose preference test which was adapted from published methods (Pothion et al., 2004). Mice were acclimatized to two water bottles in the home cage for 24 hours and individually housed approximately 4 hours prior to testing. Testing occurred during the dark phase (19:00-07:00) in which mice were presented with two bottles, one containing $1 \%$ sucrose and the other tap water. The right-left position of sucrose was counterbalanced between mice in each group. Sucrose preference was calculated as the percentage of sucrose consumed over total liquid consumed.

Novelty Suppressed feeding. Anxiety-like behaviour was assessed using the novelty suppressed feeding test (NSF), adapted from previously published methods (Samuels and Hen, 2011). Behaviour in this test is sensitive to chronic stress exposure and ovarian status (Mahmoud et al., 2016; Stedenfeld et al., 2011), and chronic antidepressant treatment produces an anxiogenic effect in a neurogenesisdependent manner in males (Santarelli et al., 2003). Briefly, mice were deprived of food for 24 hours, then individually placed in one corner of an open arena $(50 \times 50 \times 20 \mathrm{~cm})$ containing a froot loop ${ }^{\odot}$ in the centre, and latency to start feeding was measured. Testing was performed under bright light conditions, and the arena was cleaned with $70 \% \mathrm{EtOH}$ between mice. If a mouse did not feed within 10 minutes, it was removed from the arena and given a latency of 600 seconds in the analysis. Mice were returned to their home cage following testing, and food consumed within 5 minutes in the home cage was measured to account for potential appetite differences. Mice were re-grouped after the test. To avoid a 
neophobic reaction to the food, froot loops ${ }^{\odot}$ were introduced to the home cage for 3 days prior to the test.

\section{Dexamethasone suppression and HPA axis stress reactivity tests}

Disrupted HPA axis negative feedback inhibition is an endocrine hallmark of MDD (Ising et al., 2007; Stetler and Miller, 2011), and estrogens regulate HPA negative feedback function (Goel et al., 2014). Therefore, half the animals from each group were subjected to the dexamethasone (DEX) suppression test to assess the integrity of the glucocorticoid-dependent negative-feedback function of the HPA axis. DEX (i.p.; $100 \mathrm{ug} / \mathrm{kg}$ ) was administered 15 minutes prior to the regular treatment (E2, DPN, PPT, or oil). Mice were subjected to a 30-min restraint stressor starting 90 minutes after DEX administration, and blood was collected via tail vein nick at the end of restraint. To investigate HPA axis reactivity to an acute stressor, the other half of animals from each group received a vehicle injection ( $0.9 \%$ saline) in place of DEX, with the remainder of the procedure (restraint and blood collection) being identical. Blood samples were placed at $4{ }^{\circ} \mathrm{C}$ overnight, then centrifuged for $15 \mathrm{~min}$ at $1000 \mathrm{x} \mathrm{g}$ and serum aliquots were stored at $-20^{\circ} \mathrm{C}$ until processing.

\section{Tissue harvesting and processing}

Mice were euthanized approximately 2 hours after the DEX/HPA axis stress reactivity test. To obtain fixed brain tissue for immunohistochemistry, approximately half the mice in each group were deeply anesthetized with sodium pentobarbital (i.p.) then perfused with $10 \mathrm{~mL}$ of cold $0.9 \%$ saline followed by $20 \mathrm{~mL}$ of cold $4 \%$ paraformaldehyde (PFA). Brains were extracted immediately and post-fixed at $4{ }^{\circ} \mathrm{C}$ in 4\% PFA for 24 hours, then transferred to a $30 \%$ sucrose solution (in 0.1 M Phosphate Buffer; pH 7.4) and kept at $4{ }^{\circ} \mathrm{C}$ until sectioning. To obtain fresh tissue for electrochemiluminescence immunoassays, the other half of mice in each group were euthanized by rapid decapitation and brains were removed immediately and micro-dissected on a cold surface. Specifically, the entire rostral-caudal extent of the hippocampus was dissected, and the frontal cortex was collected anterior to the genu of the corpus callosum (Bregma $1.42 \mathrm{~mm}$ ). Tissue was flash-frozen on dry ice and stored at $-80^{\circ} \mathrm{C}$ until homogenized. Blood was collected via cardiac puncture from perfused mice, and trunk blood was collected from decapitated mice. In both cases, blood was collected into EDTA-coated tubes, centrifuged for 15 minutes at $4^{\circ} \mathrm{C}$ at $1000 \mathrm{x} \mathrm{g}$, then plasma aliquots were stored at $-80^{\circ} \mathrm{C}$ until processing. 


\section{Electrochemiluminescence immunoassays}

In preparation for electrochemiluminescence immunoassays (ECLIAs), frontal cortices and hippocampi were homogenized individually in cold lysis buffer $(200 \mu 1,150 \mu \mathrm{L}$, and $400 \mu \mathrm{L}$, respectively) using an Omni Bead Ruptor (Omni international, Kennesaw, GA). Homogenates were immediately centrifuged at $2600 \mathrm{rpm}$ and $4^{\circ} \mathrm{C}$ for 10 minutes, and aliquots were stored at $-80^{\circ} \mathrm{C}$ until processing. ECLIA kits from Meso Scale Discovery (MSD; Rockville MD) were used for the quantification of cytokines and PSD-95. All assays were performed in accordance with manufacturer's instructions, with samples run in duplicates. Plates were read using a Sector Imager 2400 (MSD; Rockville MD), and data were analyzed using the Discovery Workbench 4.0 software (MSD). ECLIA values were normalized to total protein concentrations, which were measured in tissue homogenates in triplicates using the Pierce Micro BCA Protein Assay Kits (ThermoFisher Scientific) according to manufacturer instructions. Cytokine quantification: Because inflammation is implicated in MDD (Dowlati et al., 2010; Enache et al., 2019; Haapakoski et al., 2015), several immune mediators were measured in the hippocampus and frontal cortex. The V-PLEX Proinflammatory Panel 1 kit (mouse) from MSD (catalogue no. K15048D) was used, which allows for the concurrent quantification of Interleukin-1beta (IL-1 $\beta$ ), Interleukin-2 (IL-2), Interleukin-4 (IL-4), Interleukin-6 (IL-6), Interleukin-10 (IL-10), Interferongamma (IFN- $\gamma$ ), tumor necrosis factor- $\alpha$ (TNF- $\alpha$ ), chemokine (C-X-C motif) ligand 1 (CXCL1), Granulocyte-macrophage colony-stimulating factor (GM-CSF), and vascular endothelial growth factor (VEGF), thus provides a comprehensive picture of the inflammatory state. The following lower limits of detection (LLODs) were observed: IL-1 $\beta$ : 0.74-0.88 pg/ml; IL-2: 2.1-2.6 pg/ml; IL-4: 0.350.45 pg/ml; IL-6: 5.6-6.2 pg/ml; IL-10: 1.1-1.8 pg/ml; IFN- $\gamma: 0.07-0.11$ pg/ml; TNF- $\alpha: 0.88-1.32$ pg/ml; CXCL1: 0.17-0.36 pg/ml; GM-CSF: 0.09- 0.13 pg/ml; and VEGF: 0.31-0.38 pg/ml. Values below the LLOD were assigned 0pg/mL, as published previously (Bodnar et al., 2017; Eid et al., 2019a).

PSD-95 quantification: PSD-95 was quantified because its expression is regulated by E2, DPN and PPT in the hippocampus of female rats and mice (Li et al., 2004; Waters et al., 2009) and because it's reduced in the PFC of individuals with MDD (Feyissa et al., 2009) and with chronic stress exposure in rodents (Kallarackal et al., 2013; Kim and Leem, 2016; Pacheco et al., 2017). PSD-95 protein expression was quantified in hippocampus and frontal cortex samples using a PSD-95 kit from MSD (catalogue no. K150QND). 


\section{Immunohistochemistry}

For immunohistochemical staining, PFA-fixed brains were sliced into $30 \mu \mathrm{m}$ coronal sections using a Leica SM2000R Microtome (Richmond Hill, Ontario, Canada). Sections were stored at $-20{ }^{\circ} \mathrm{C}$ in a cryoprotective solution containing 20\% glycerol (Sigma-Aldrich, St. Louis, MO, USA) and 30\% ethylene glycol (Sigma-Aldrich) in 0.1 M phosphate-buffer (PB, pH 7.4). Tissue was rinsed in 0.1M phosphate-buffered saline (PBS; pH 7.4; 3 x $10 \mathrm{~min}$ ) to remove the cryoprotectant prior to staining and between all incubations. Unless otherwise noted, all incubations were performed on a rotator and at room temperature.

BrdU/NeuN: We examined the co-expression of BrdU with the neuronal marker NeuN to determine the proportion of BrdU immunoreactive (ir) cells that are neurons. Sections incubated for 24 hours at $4^{\circ} \mathrm{C}$ in a primary antibody solution containing mouse anti-NeuN (catalogue no. MAB377; Millipore, Billerica, MA, USA) diluted 1:250 in 0.3\% Triton-X and 3\% normal donkey serum (NDS) in 0.1M PBS. Sections were then transferred to a secondary antibody solution containing 1:200 donkey antimouse Alexa Fluor 488 (Invitrogen, Burlington, ON, Canada) and incubated for 24 hours at $4{ }^{\circ} \mathrm{C}$. Sections were fixed in 4\% PFA (in $0.1 \mathrm{PBS} ; 1 \times 10 \mathrm{mins}$ ) followed by $0.9 \%$ saline ( 2 x $10 \mathrm{mins}$ ), before being transferred to $2 \mathrm{~N} \mathrm{HCL}$ for $30 \mathrm{mins}$ at $37^{\circ} \mathrm{C}$. Sections were then incubated for 24 hours at $4^{\circ} \mathrm{C}$ in a primary antibody solution containing rat anti-BrdU (catalogue no. ab6326; Abcam, Cambridge, UK) diluted 1:500 in 0.3\% Triton-X and 3\% NDS in 0.1M PBS. Sections were transferred to a secondary antibody solution containing 1:500 donkey anti-rat Alexa Fluor 594 (Jackson ImmunoResearch) in 0.1M PBS for 24 hours. Sections were finally mounted onto glass slides (Superfrost Plus; Fisher scientific, Pittsburgh, PA, USA) and cover-slipped with polyvinyl alcohol (PVA)-DABCO (Sigma-Aldrich).

Ionized calcium binding adaptor molecule-1 (Iba-1): Iba-1 is a calcium-binding protein commonly utilized as a microglial marker (Korzhevskii and Kirik, 2016). Microglia were investigated as positron emission tomography studies provide evidence of increased microglial activation in MDD, and this effect is associated with illness duration and correlated with depression severity (Setiawan et al., 2018, 2015). Hippocampal and ventromedial prefrontal cortex (vmPFC) sections were incubated for 25 min in $0.3 \%$ hydrogen peroxide (in $\mathrm{dH}_{2} \mathrm{O}$ ) then blocked for $1 \mathrm{~h}$ with $10 \%$ normal goat serum (NGS) and $0.5 \%$ Triton-X in $0.1 \mathrm{M}$ PBS. Sections were transferred to a primary antibody solution containing rabbit antiIba-1 (1:1000; catalogue no. 019-19741; Wako, Osaka, Japan) in 10\% NGS and 0.4\% Triton-X in 0.1M PBS and incubated at $4^{\circ} \mathrm{C}$ for 20 hours. Next, sections were incubated in a secondary antibody solution for 1 hour, consisting of 1:500 biotinylated goat anti-rabbit (Vector Laboratories) in 2.5\% NGS and 
0.4\% Triton X in PBS. Sections were then incubated for $1 \mathrm{~h}$ in ABC (Elite kit; 1:50, Vector Laboratories) in $0.4 \%$ Triton-X in PBS, then immunoreactants were visualized with a 7 min diaminobenzidine (DAB) reaction (Vector Laboratories). Sections were mounted on glass slides, allowed to dry, then dehydrated in increasing graded ethanol solutions, cleared with xylene, and coverslipped with Permount (Fisher Scientific).

\section{Microscopy, cell quantification, and optical density}

BrdU- immunoreactive (ir) cell quantification was performed by an experimenter blinded to group assignment under a 100x objective on an Olympus BX51 brightfield microscope equipped with epifluorescence. A representative photomicrograph is depicted in Fig. 4C. BrdU-ir cells were exhaustively quantified in every $10^{\text {th }}$ section of the hippocampus specifically within the granule cell layer (GCL) and the subgranular zone (SGZ), defined as the 50 $\mathrm{m}$ band between the GCL and hilus. Cells were quantified separately in the dorsal and ventral hippocampus as these regions have distinctive functions (Fanselow and Dong, 2010) Raw counts were multiplied by 10 to obtain an estimate of the total number of BrdU-ir cells in the hippocampus (Mahmoud et al., 2016a; Pan et al., 2012). BrdU-ir cells were examined for NeuN co-expression to estimate the proportion of BrdU-ir cells that are neurons (calculated as BrdU/NeuN co-labeled cells divided by the total number of BrdU-ir cells). Then, to obtain a neurogenesis index for each animal, the estimated total number of BrdU-ir cells was multiplied by the ratio of BrdU/NeuN co-labeled cells.

Optical density of Iba-1 expression was measured using ImageJ in images obtained using CellSens software (Olympus) at 10x with fixed gain and exposure settings, as we have done previously (Wainwright et al., 2016; Workman et al., 2015). Six sections were sampled per animal, including two sections each for the dorsal hippocampus (Bregma -1.66 to -2.35mm), ventral hippocampus (Bregma 3.18 to $-3.58 \mathrm{~mm}$ ), and vmPFC (Bregma 1.54 to $1.94 \mathrm{~mm}$, with infralimbic (IL) and prelimbic (PL) regions sampled separately). Background grey value was obtained in each image from an average of open ellipses placed randomly in 10 non-immunolabeled areas, and threshold for immunoreactivity was set at 3-times the mean background grey value. In hippocampal slices, the GCL, SGZ and an approximately $50 \mu \mathrm{m}$ band of the molecular layer (ML) were traced and mean grey value per area was calculated. In vmPFC slices, mean grey value per area was measured in two $0.85 \mathrm{~mm}^{2}$ regions placed within the IL and PL regions. 


\section{Vaginal cytology for estrous cycle staging}

Behaviour, immune, and neural measures can be affected by estrous cycle stage (Beagley and Gockel, 2003; Meziane et al., 2007; Woolley et al., 1990). Therefore, vaginal cells were collected by lavage from sham-operated mice on all behavioural testing days and prior to euthanasia, and estrous cycle stage was determined according to previous methods (Cora et al., 2015). To account for potential effects of the procedure, all ovariectomized mice were also lavaged.

\section{Radioimmunoassays for corticosterone quantification}

Corticosterone concentrations were measured in serum samples obtained from HPA axis stress reactivity and DEX suppression tests. Corticosterone double-antibody radioimmunoassay kits (MP biomedicals, Solon, $\mathrm{OH}$ ) were used according to manufacturer's instructions and the Inter- and intraassay coefficients of variation were $<10 \%$.

\section{Statistical analyses}

Statistica software (Tulsa, OK) was used for all analyses. Behavioural measures (FST, TST, NSF, and SPT), cytokines, and CORT concentrations were each analyzed by factorial analysis of variance (ANOVA) with treatment (Sham, OVX, E2, DPN, PPT) and stress condition (CUS, no-CUS) as the between-subject factors. Neurogenesis index, proportion of of BrdU/NeuN co-labeled cells, PSD-95 expression, and Iba-1 optical density were each analyzed using repeated measures ANOVA with treatment (Sham, OVX, E2, DPN, PPT) and stress condition (CUS, no-CUS) as the between-subject factors and brain region (dorsal and ventral hippocampus, or hippocampus and frontal cortex) as the within-subject factors. Given that 10 cytokines were measured in each brain region, Principal Component Analyses (PCAs) were used as a dimensionality reduction tool (Jolliffe, 2002; Ringner, 2008). PCA reduces the number of potentially correlated variables (in this case cytokines) into a small set of uncorrelated variables called Principal Components (PCs). These components are ordered such that the first PC (PC1) accounts for most of the variance within the data. This approach was used to derive information about the amount of variance in the data that can be accounted for by potential cytokine networks. Because PCA does not take into account group membership, ANOVAs were subsequently applied to individual PC scores as we have published previously (Eid et al., 2019a), in order to explore the effects of treatments and CUS exposure on cytokine networks. DEX was used as a covariate in all cytokine analyses as DEX was administered to half the animals on tissue collection day, and because glucocorticoids have anti-inflammatory effects (Bereshchenko et al., 2018). Body mass was used as a covariate when analyzing immobility in FST. Estrous cycle stage was used as a covariate 
for all analyses. Covariate effects are only reported when significant. Neuman-Keul's comparisons were used for post-hoc analyses and any a priori comparisons employed were subjected to Bonferroni correction. Outliers that fell more than 2.5 standard deviations away from the mean were removed from analyses. Significance was set at $\alpha=0.05$. Were appropriate, effect sizes are given as partial $\eta^{2}$ or Cohen's d.

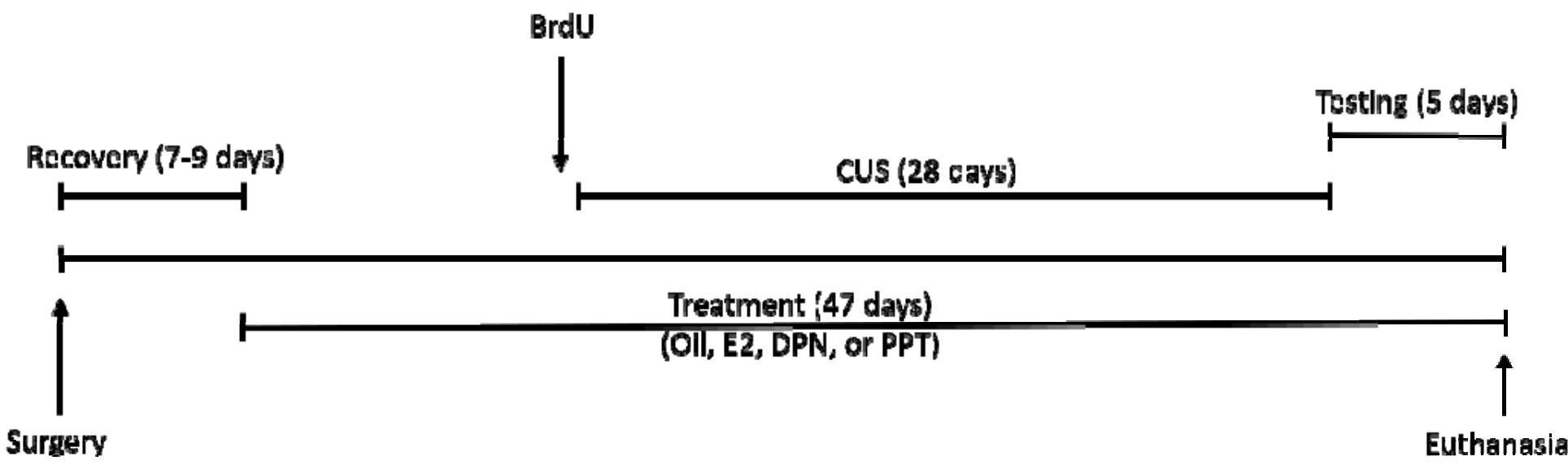

Figure 1. Timeline depicting the sequence of experimental events. Ovariectomy or Sham surgery was performed at approximately 3 months of age. Following 7-9 days of recovery, all mice received daily subcutaneous treatment (oil, E2, DPN, or PPT) until experimental endpoint (47 days total). On treatment day 14 all mice received two BrdU injections. Starting on treatment day 15, half the mice from each treatment group were subjected to chronic unpredictable stress (CUS; 28 days). Behavioural tests were administered starting the day after CUS in the following order (one test/day): forced swim test, sucrose preference test, novelty suppressed feeding test, and tail suspension test. On the final day of the experiment mice were subjected to the dexamethasone suppression test or the HPA axis stress reactivity test before tissue harvesting.

\section{Results}

TST: 1) CUS increased immobility, and this effect was primarily driven by ER agonists groups. 2) Ovariectomy increased immobility, and this effect was prevented by estrogenic treatments only under no-CUS Conditions.

As expected, CUS significantly increased immobility in the TST (main effect of CUS condition: F(1, 111) $=11.96, p<0.001, \eta_{p}^{2}=0.097$; Fig. 2A $)$. This effect of CUS to increase immobility was clearly driven by the ER agonist groups (PPT and DPN; both p's < 0.0052, Cohen's $d=0.88-1.1$, relative to no-CUS counterparts; Fig. 2A 2 -3), and to a lesser extent by the E2 group ( $\mathrm{p}=0.10$, relative to no-CUS counterparts; a priori comparisons: treatment by CUS condition interaction: $\mathrm{p}=0.19$ ). Further, ovariectomy increased immobility in the TST relative to Sham and DPN groups (p's <0.03, Cohen's $d$ $=0.7-1.0$; main effect of treatment: $F(4,111)=3.06, p=0.02, \eta_{p}^{2}=0.099$; Fig. 2A2). Upon closer examination, this ovariectomy-induced increase in immobility was prevented by E2, DPN, and PPT 
treatments under no-CUS conditions only (p's <0.04; a priori comparisons, treatment by CUS condition interaction: $\mathrm{p}=0.19$; Fig. 2A3 ). In an additional exploratory analysis of TST data, we performed a median split and categorized mice into low immobility or "resilient", versus high immobility or "susceptible" phenotypes, adapted from previous reports (Wells et al., 2017). We then performed a Chi-square test to compare the frequency of mice that were susceptible versus resilient between groups under CUS conditions: $\chi^{2}(9)=16.17, p=0.06$ (frequencies reported in Table 2). In the CUS exposed mice only, OVX mice displayed a bias towards a susceptible phenotype, whereas shamoperated mice displayed a bias towards a resilient phenotype. Further, a bias towards a susceptible phenotype is seen in PPT-treated groups, whereas E2- and DPN-treated groups showed an even split of resilient and susceptible mice after CUS.

\section{Ovariectomy reduced latency to feed in NSF regardless of CUS exposure, and this effect was prevented by $\mathrm{E} 2$ treatment}

Regardless of CUS condition, OVX significantly reduced latency to feed in NSF in comparison to Sham ( $\mathrm{p}=0.029$, Cohen's $d=0.63$; main effect of treatment: $\mathrm{F}(4,111)=3.99, \mathrm{p}=0.005, \eta_{\mathrm{p}}^{2}=0.13$; Fig 2B). This effect of OVX to reduce latency to feed was prevented by E2 ( $\mathrm{p}=0.92$, relative to Sham) but not by DPN or PPT treatments (p's <0.05, relative to Sham). There was no significant main effect of
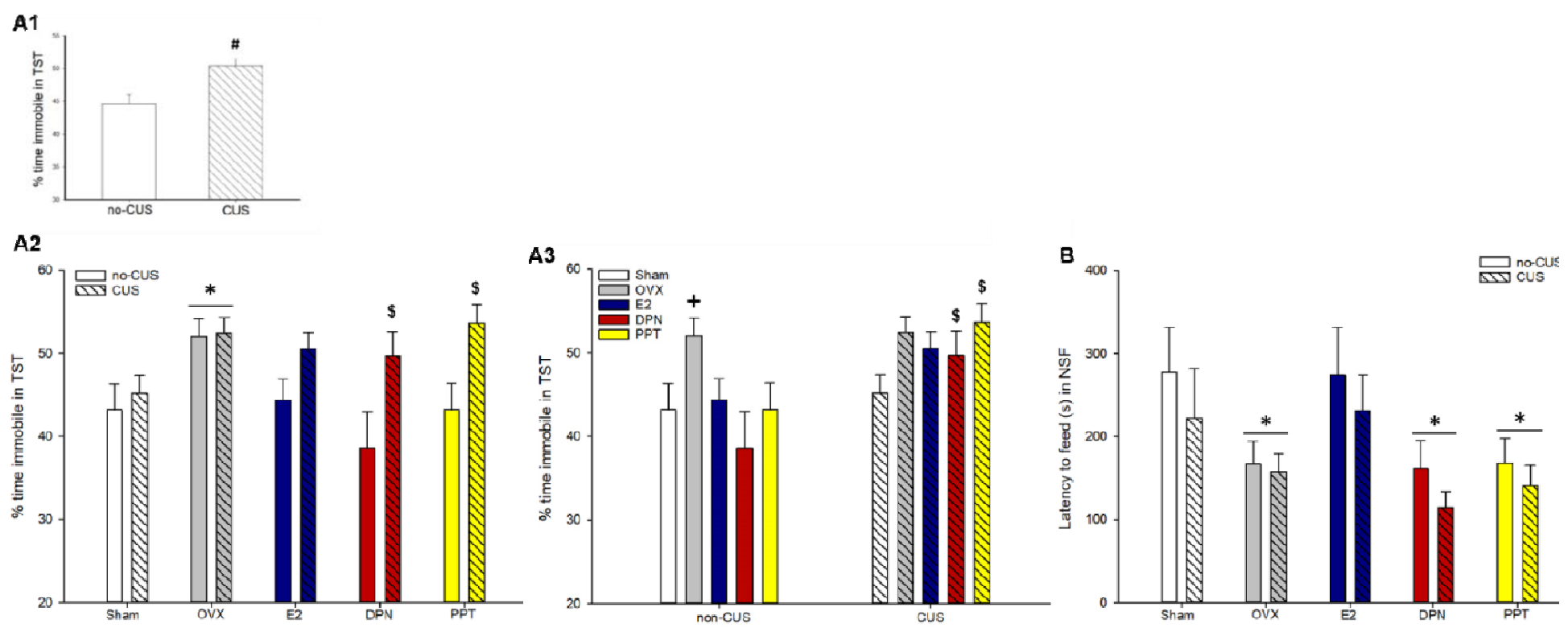

CUS condition nor a treatment by CUS condition interaction (p's $>0.15$ ).

Figure 2. Percentage of time spent immobile in the tail suspension test (A1-3), and latency to feed in the novelty suppressed feeding test (B). Figures A2 and A3 depict the same data, organized differently across the $\mathrm{x}$-axis for clarity of effects. (A1) CUS significantly increased immobility in TST; \# indicates $\mathrm{p}<0.001$, main 
effect of CUS condition. (A2, A3) The effect of CUS to increase immobility was primarily driven by DPN- and PPT-treated groups; $\$$ indicate p's $<0.0052$, significantly higher than no-CUS treatment counterparts. (A2) Ovariectomy significantly increased immobility, * indicates $\mathrm{p}<0.03$, relative to Sham and DPN. (A3) the effect of ovariectomy to increase immobility was prevented by all estrogenic treatments only under non-CUS conditions only; + indicates p's $<0.05$, relative to all non-CUS groups. (B) Ovariectomy significantly decreased latency to feed in NSF, and this effect was prevented by E2 treatment only, * indicate $\mathrm{p}<0.05$, relative to sham. TST, tail suspension test; NSF, novelty suppressed feeding; CUS, chronic unpredictable stress; OVX, ovariectomized; E2, estradiol; DPN, diarylpropionitrile; PPT, propylpyrazole-triol. Data in means + standard error of the mean.

\section{There were no significant group differences in FST immobility or sucrose preference}

There were no significant group differences in \% time spent immobile in the FST or \% sucrose preference (p's >0.11 for main effects of CUS condition and treatment and their interaction; Table 2).

Table 2. Percent time spent immobile in the forced swim test, percent sucrose preference $( \pm$ standard error of the mean), and frequency of resilient versus susceptible in the tail suspension test.

\begin{tabular}{lllcc}
\hline Group & $\begin{array}{l}\text { \% time spent immobile in } \\
\text { FST }\end{array}$ & \% sucrose preference & $\begin{array}{l}\text { \# of resilient in TST } \\
\text { (low immobility) }\end{array}$ & $\begin{array}{c}\text { \# of susceptible in TST } \\
\text { (high immobility) }\end{array}$ \\
\hline no-CUS & & & & \\
\hline Sham & $47.75 \pm 3.49$ & $82.24 \pm 6.49$ & 7 & 10 \\
OVX & $45.69 \pm 5.11$ & $84.62 \pm 3.37$ & 4 & 5 \\
E2 & $51.60 \pm 4.97$ & $89.64 \pm 1.51$ & 9 & 3 \\
DPN & $48.27 \pm 4.28$ & $87.79 \pm 2.25$ & 8 & 5 \\
PPT & $41.35 \pm 3.81$ & $86.26 \pm 1.93$ & 9 & 3 \\
\hline CUS & & & & 9 \\
\hline Sham & $41.92 \pm 3.49$ & $90.92 \pm 2.26$ & 4 & 7 \\
OVX & $42.38 \pm 3.86$ & $90.98 \pm 0.81$ & 6 & 7 \\
E2 & $47.84 \pm 2.97$ & $89.86 \pm 3.84$ & 6 & 10 \\
DPN & $41.72 \pm 3.35$ & $92.75 \pm 1.30$ & 3 & 7 \\
PPT & $42.94 \pm 4.15$ & $81.06 \pm 3.95$ & 9 & 5 \\
\hline
\end{tabular}

No significant group differences were observed. CUS, chronic unpredictable stress; Sham, sham-operated; OVX, ovariectomized; E2, estradiol; DPN, diarylpropionitrile; PPT, propylpyrazole-triol; FST, forced swim test; NSF, novelty suppressed feeding, TST; tail suspension test.

\section{E2 treatment reduced CORT response to acute restraint stress}

In the HPA axis stress reactivity test, E2 treatment reduced post-restraint stress CORT concentrations relative to all other treatment groups (p's $<0.025$, Cohen's $d=0.6-1.8$; main effect of treatment: $\mathrm{F}(4$, 
49)=3.96, p=0.007, $\eta_{p}^{2}=0.24$; Fig. 3A). There was no significant main effect of CUS condition nor a treatment by CUS condition interaction (p's >0.4).

\section{CUS enhanced the dexamethasone suppression of CORT in most treatment groups}

In the DEX suppression test, CUS exposure significantly reduced post-restraint stress CORT concentrations in Sham ( $\mathrm{p}=0.0015$, Cohen's $d=1.8$ ), OVX ( $\mathrm{p}=0.00057$, Cohen's $d=2.0$ ), and DPN ( $\mathrm{p}=0.011$, Cohen's $d=2.5$ ) groups, with a trend in PPT ( $\mathrm{p}=0.06)$, but not in E2 ( $\mathrm{p}=0.9$; Fig 3B; treatment by CUS condition interaction: $\left.F(4,51)=3.42, p=0.015, \eta_{p}^{2}=0.21\right)$. Further, E2 treated mice had sigificantly lower CORT concentrations relative to all treatment groups in the no-CUS condition $(\mathrm{p}<0.01$; Fig 3B) except PPT $(\mathrm{p}=0.15)$. There were also significant main effects of treatment and stress condition (p's $<0.001$ ).
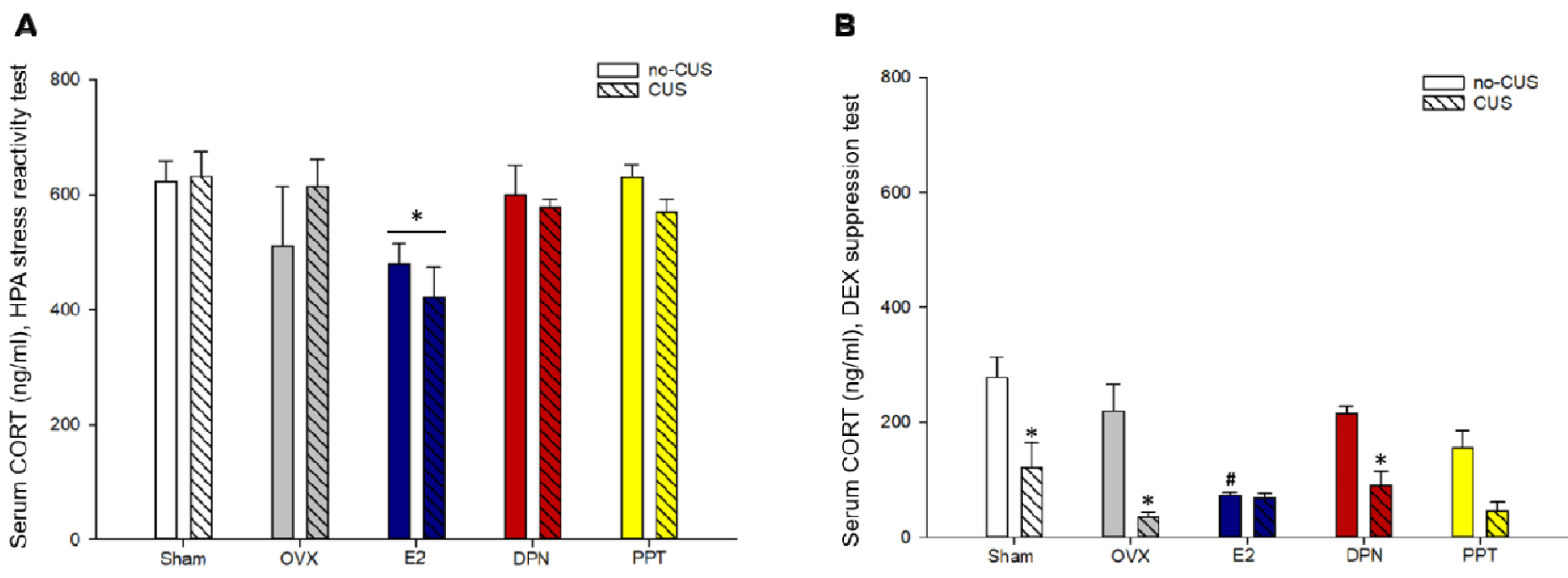

Figure 3. Serum corticosterone concentrations in the hypothalamic-pituitary-adrenal (HPA) axis stress reactivity test (A) and dexamethasone (DEX) suppression test (B). (A) E2 treatment reduced serum corticosterone concentrations immediately following an acute restraint stressor; * indicates $\mathrm{p}<0.025$ relative to all other treatment groups. (B) CUS exposure significantly enhanced dexamethasone suppression of corticosterone in Sham, OVX and DPN groups, and a similar but non-significant trend was detected with PPT treatment (* indicates $\mathrm{p}<0.02$ relative to no-CUS counterparts). Further, under no-CUS conditions E2 treatment reduced corticosterone concentrations (\# indicates $\mathrm{p}<0.01$ relative to Sham, OVX, and DPN treated no-CUS groups). CUS, chronic unpredictable stress; OVX, ovariectomized; E2, estradiol; DPN, diarylpropionitrile; PPT, propylpyrazole-triol. Data in means + standard error of the mean.

\section{CUS exposure reduced the proportion of BrdU-ir cells that expressed NeuN in ventral dentate} gyrus

In the ventral dentate gyrus only, CUS exposure reduced the proportion of BrdU/NeuN co-labeled cells ( $\mathrm{p}=0.04$, Cohen's $d=0.4$; region by CUS condition interaction: $\mathrm{F}(1,53)=5.73, \mathrm{p}=0.02$; Table 3 ).

Further, the proportion of BrdU/NeuN co-labeled cells was overall higher in the dorsal, compared to 
the ventral, dentate gyrus (main effect of region: $F(1,53)=14.508, p=0.0004 . \eta_{p}^{2}=0.2$ ). There was also a trend for a region by treatment interaction $(\mathrm{p}=0.08)$, where, intriguingly, E2 increased the proportion of dorsal BrdU-ir cells that also expressed NeuN, suggesting a promotion of cell fate to neuronal phenotype with chronic E2, regardless of stress condition (compared to OVX and Sham p's <0.008; a priori comparisons). There were no other significant main effects or interactions (p's $>0.2$ ).

Table 3. Proportion of BrdU/NeuN co-labeled cells in dorsal and ventral dentate gyrus (mean \pm standard error of the mean)

$\left.\begin{array}{lll}\hline \text { Group } & \text { Dorsal ratio } & \text { Ventral ratio } \\ \hline \hline \text { no-CUS } & & \\ \hline \text { Sham } & 0.60 \pm 0.079 & 0.70 \pm 0.028 \\ \text { OVX } & 0.73 \pm 0.067 & 0.65 \pm 0.052 \\ \text { E2 } & 0.81 \pm 0.028^{s} & 0.73 \pm 0.031 \\ \text { DPN } & 0.73 \pm 0.052 & 0.72 \pm 0.031 \\ \text { PPT } & 0.70 \pm 0.046 & 0.64 \pm 0.067 \\ \hline \text { CUS } & & \\ \hline \text { Sham } & 0.69 \pm 0.042 & 0.61 \pm 0.094 \\ \text { OVX } & 0.67 \pm 0.052 & 0.62 \pm 0.084 \\ \text { E2 } & 0.83 \pm 0.017^{s} & 0.56 \pm 0.062 \\ \text { DPN } & 0.79 \pm 0.023 & 0.64 \pm 0.064 \\ \text { PPT } & 0.77 \pm 0.055 & 0.70 \pm 0.014\end{array}\right] *$

* indicates CUS exposure significantly reduced the proportion of BrdU/NeuN co-labeled cells only in the ventral dentate gyrus, $\mathrm{p}=0.04$. $\$$ indicates $\mathrm{E} 2$ increased the proportion of BrdU/NeuN co-labeled cells only in the dorsal dentate gyrus, but regardless of CUS condition, $\mathrm{p}<0.008$, compared to OVX and Sham groups. BrdU: bromodeoxyuridine CUS, chronic unpredictable stress; Sham, sham-operated; OVX, ovariectomized; E2, estradiol; DPN, diarylpropionitrile; PPT, propylpyrazole-triol.

\section{CUS reduced neurogenesis in the ventral dentate gyrus and $\mathrm{E} 2$ increased neurogenesis in the}

\section{dorsal dentate gyrus}

Irrespective of CUS exposure, E2 significantly increased neurogenesis index in the dorsal GCL only, relative to all other treatments (all p's $<0.0003$, Cohen's $d=0.7-1.2$; region by treatment interaction: $\left.\mathrm{F}(4,53)=3.37, \mathrm{p}=0.016, \eta_{\mathrm{p}}^{2}=0.2 ; \mathbf{F i g} \mathbf{4 A}\right)$. CUS exposure reduced neurogenesis in the ventral dentate gyrus ( $\mathrm{p}=0.05$, Cohen's $d=0.5$ ) but not in the dorsal dentate gyrus ( $\mathrm{p}=0.28$; region by CUS condition interaction: $F(1,53)=7.48, p=0.008, \eta_{p}^{2}=0.12$; Fig 4B). There were also significant main effects of treatment and region (p's <0.04) but no other main effects or interactions (p's $>0.5$ ). 
A
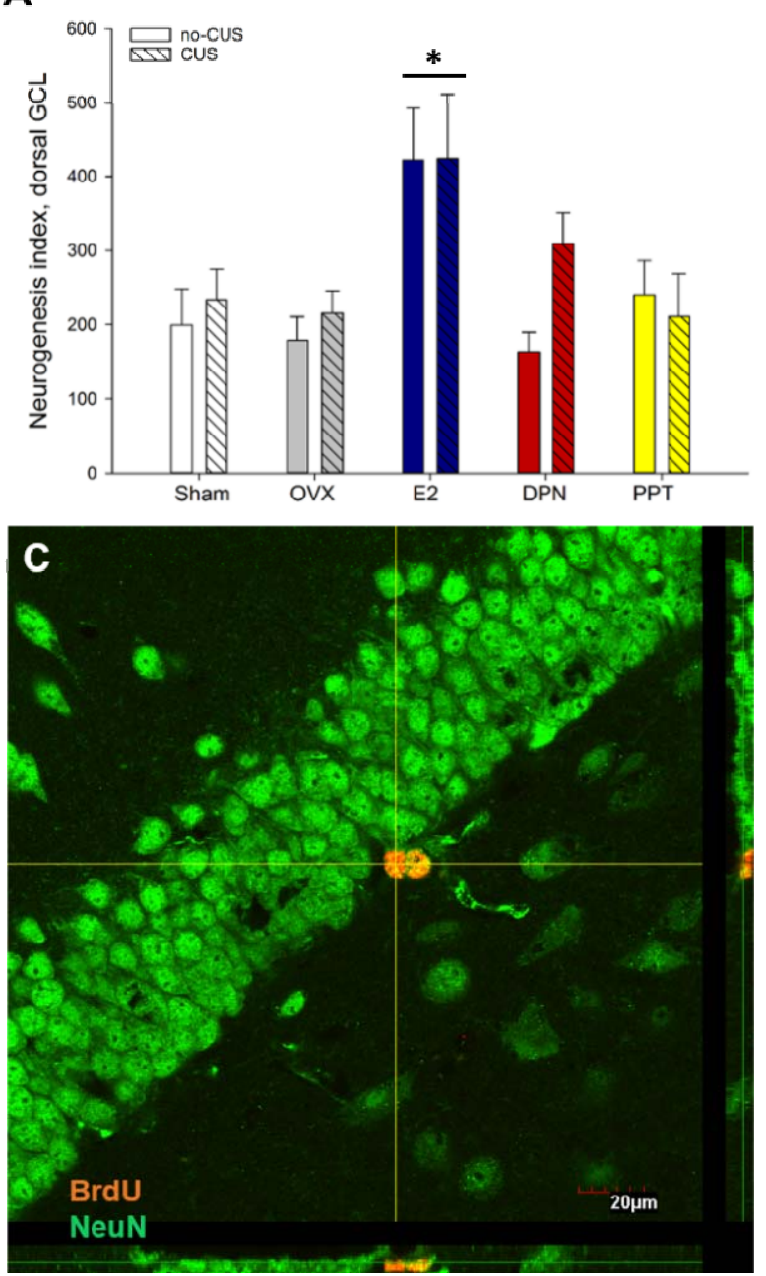

$\mathbf{B}$

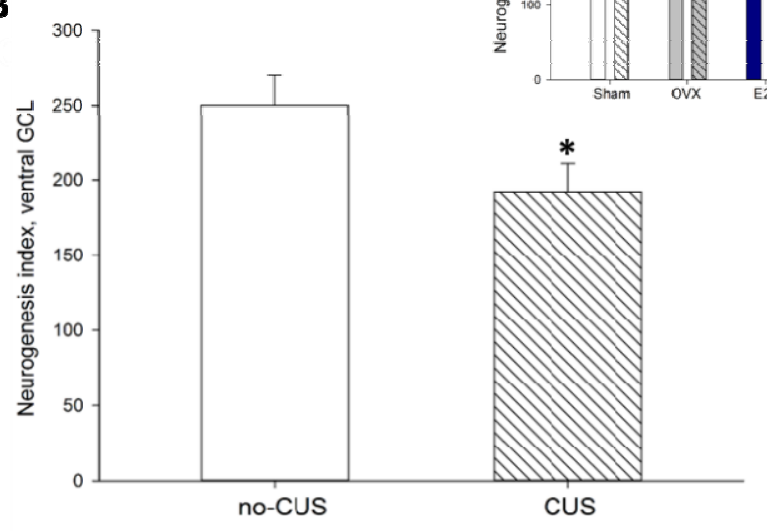

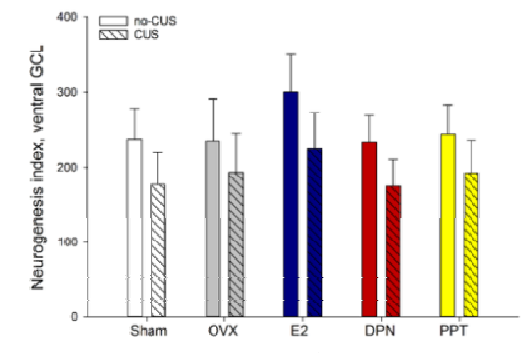

Figure 4. Neurogenesis index in the dorsal (A) and ventral (B) dentate gyrus. (A) Estradiol treatment significantly increased neurogenesis in the dorsal granule cell layer (GCL); * indicates $\mathrm{p}<0.0003$ relative to all other treatment groups. (B) CUS exposure significantly reduced neurogenesis in the ventral GCL; * indicates $\mathrm{p}$ $=0.05$ relative to no-CUS. Inset graph depicts the data by treatment and CUS condition. (C) Representative photomicrographs of the granule cell layer $(\mathrm{GCL})$ of the dentate gyrus, obtained at 60x magnification showing two BrdU-ir cells (orange) co-expressing NeuN (green). GCL, granule cell layer BrdU, bromodeoxyuridine; CUS, chronic unpredictable stress; OVX, ovariectomized; E2, estradiol; DPN, diarylpropionitrile; PPT, propylpyrazole-triol. Data in means + standard error of the mean. 


\section{CUS exposure decreased PSD-95 expression in the hippocampus and frontal cortex, and this}

\section{effect was observed primarily in DPN- and PPT-treated groups}

CUS exposure significantly decreased PSD-95 expression in the hippocampus and frontal cortex (main effect of CUS condition: $F(1,45)=7.89, p=0.007, \eta_{p}^{2}=0.15$; Fig 5A). The effects of CUS to decrease PSD-95 were largely driven by PPT and DPN groups (p's $<0.05$, relative to non-CUS counterparts; CUS condition by treatment interaction: $\left.F(4,45)=2.67, p=0.044, \eta_{p}^{2}=0.19\right)$. Further, PSD-95 expression was overall significantly higher in the hippocampus than the frontal cortex (main effect of region: $\mathrm{F}(1,45)=98.18, \mathrm{p}<0.001 \eta_{\mathrm{p}}^{2}=0.69$; Fig 5B). There were no other main effects or interactions (all p's >0.1).
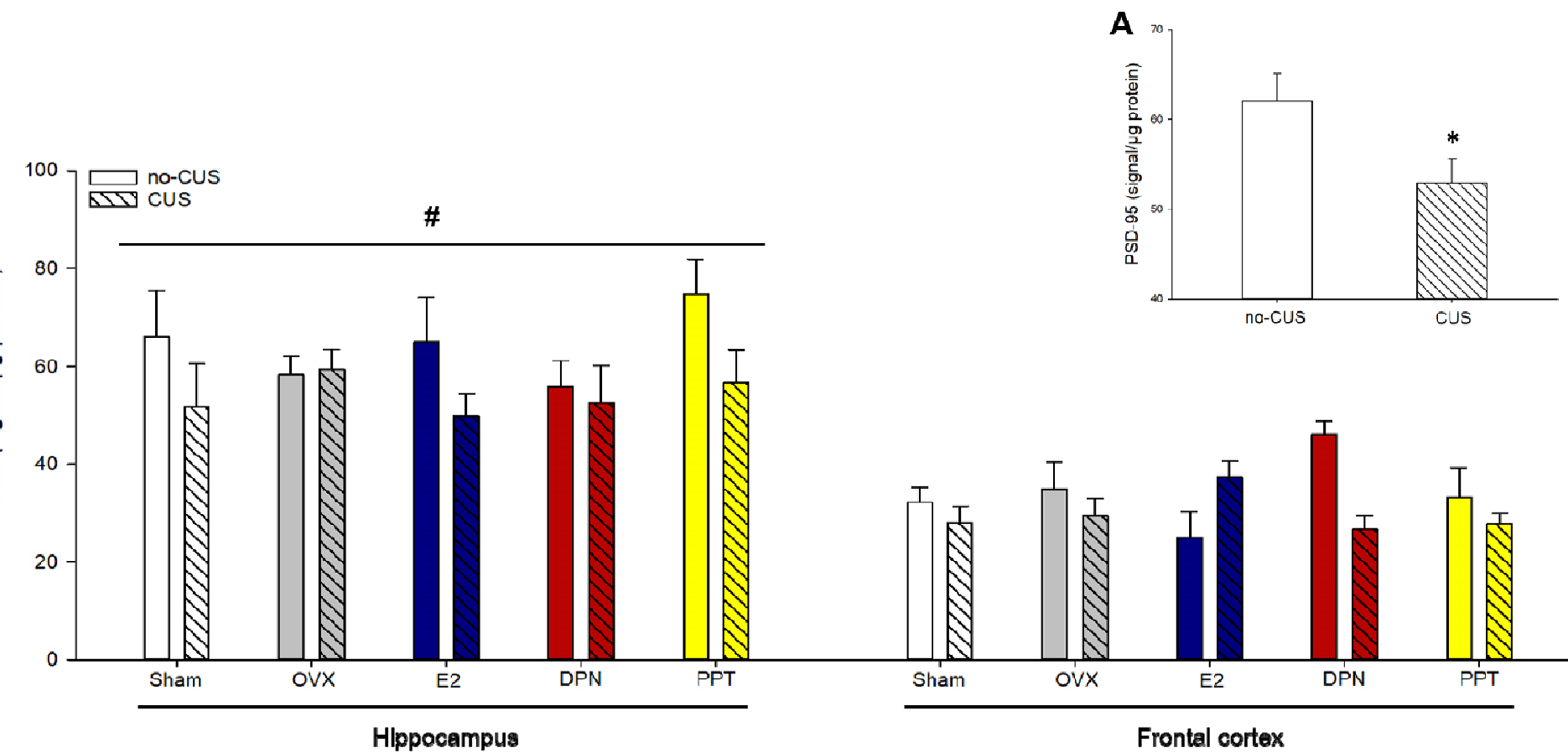

Figure 5. Postsynaptic density protein 95 (PSD-95) expression in the hippocampus and frontal cortex, normalized by total protein concentrations. (A) CUS exposure decreased PSD-95 expression in both regions; * indicate $\mathrm{P}=0.007$, main effect of CUS condition. (B) PSD-95 expression was significantly higher in the hippocampus in comparison with the frontal cortex. \# indicates $\mathrm{p}<0.001$, main effect of region. PSD-95, postsynaptic density-95; CUS, chronic unpredictable stress; OVX, ovariectomized; E2, estradiol; DPN, diarylpropionitrile; PPT, propylpyrazole-triol. Data in means + standard error of the mean. 


\section{Cytokine PCA results}

\section{CUS increased PC1 scores in the hippocampus, an effect driven primarily by Sham and DPN- treated groups, and Sham-operated mice had lower PC2 scores}

The model generated two principal components, accounting for $57.5 \%$ of the variance within the dataset, with variance explained by principal component $1(\mathrm{PC} 1)=39.7 \%$, and $\mathrm{PC} 2=17.8 \%$. Factor loadings are shown in Table 4. ANOVA results reveal that CUS exposure increased PC1 scores (main effects of CUS condition: $F(1,53)=6.2920, p=0.015, \eta_{p}^{2}=0.11$; Fig. 6A), a significant covariate effect of DEX to reduce scores ( $\mathrm{p}=0.002)$, but no significant main effect of treatment $(\mathrm{p}=0.45)$. The effect of CUS exposure to increase PC1 scores appears to be driven by Sham and DPN groups ( $\mathrm{p}=0.027$ and 0.017, relative to no-CUS counterparts; a priori comparisons, CUS condition by treatment interaction: $\mathrm{F}(4,53)=1.63, \mathrm{p}=0.18)$. PC2 scores were lower in Sham relative to all other treatment groups (p's $<0.02$; main effect of treatment: $F(4,52)=3.39, p=0.016, \eta_{p}^{2}=0.21$; Fig. 6B), but this missed significance in comparison to PPT treatment $(\mathrm{p}=0.08)$. There was also trend toward significance for CUS to reduce PC2 scores $(\mathrm{p}=0.07)$, but no significant CUS condition by treatment interaction $(\mathrm{F}(4$, 52) $=1.3093, \mathrm{p}=0.28)$.

\section{CUS increased PC1 scores in the frontal cortex, an effect driven primarily by PPT treatment}

The model generated two principal components, accounting for $71.4 \%$ of the variance within the dataset, with variance explained by $\mathrm{PC} 1=53.2 \%$ and $\mathrm{PC} 2=18.2 \%$. Factor loadings are shown in Table 4. ANOVA results show that CUS exposure significantly increased PC1 scores (main effect of CUS condition: $F(1,45)=13.43, p=0.00065, \eta_{p}^{2}=0.23$; Fig. 6C). This effect appears to be driven by PPT-treated mice ( $\mathrm{p}=0.003$; relative to no-CUS counterparts) with a trend toward significance in OVX ( $\mathrm{p}=0.068$; a priori comparisons; treatment by CUS condition interaction: $\mathrm{F}(4,45)=1.12$, $\mathrm{p}=0.36$ ). There was also a significant covariate effect of DEX $(\mathrm{p}=0.024)$, but no significant main effect of treatment $(\mathrm{p}=0.14)$. PC2 scores were not significantly affected by treatment, CUS condition, nor their interaction (p's >0.1; Fig. 6D), but there was a significant covariate effect of DEX (p=0.009). 
bioRxiv preprint doi: https://doi.org/10.1101/758862; this version posted November 22, 2019. The copyright holder for this preprint (which was not certified by peer review) is the author/funder, who has granted bioRxiv a license to display the preprint in perpetuity. It is made available under aCC-BY-NC-ND 4.0 International license.

Table 4. Principle component analyses loading table.

\begin{tabular}{l|ll|ll}
\hline & \multicolumn{2}{|c|}{ Hippocampus } & \multicolumn{2}{c}{ Frontal cortex } \\
\hline Variable & PC1 & PC2 & PC1 & PC2 \\
\hline GM-CSF & 0.52 & -0.18 & 0.20 & 0.81 \\
IFN- $\boldsymbol{\gamma}$ & 0.71 & 0.38 & $\mathbf{0 . 7 8}$ & 0.20 \\
IL-10 & 0.90 & -0.06 & $\mathbf{0 . 8 9}$ & 0.15 \\
IL-1 $\beta$ & 0.87 & -0.30 & $\mathbf{0 . 9 0}$ & -0.07 \\
IL-2 & 0.59 & -0.63 & $\mathbf{0 . 8 0}$ & 0.14 \\
IL-4 & 0.64 & 0.30 & $\mathbf{0 . 7 3}$ & 0.15 \\
IL-6 & $\mathbf{0 . 4 1}$ & $\mathbf{0 . 5 6}$ & $\mathbf{0 . 9 1}$ & -0.05 \\
CXCL1 & 0.11 & $\mathbf{0 . 6 4}$ & -0.22 & $\mathbf{0 . 6 8}$ \\
TNF- $\alpha$ & $\mathbf{0 . 8 2}$ & -0.12 & $\mathbf{0 . 9 4}$ & -0.13 \\
VEGF & 0.15 & $\mathbf{0 . 5 2}$ & -0.37 & $\mathbf{0 . 7 6}$ \\
\hline
\end{tabular}

High loadings (> 0.4) indicated in bold text. CUS, chronic unpredictable stress; Sham, sham-operated; OVX, ovariectomized; E2, estradiol; DPN, diarylpropionitrile; PPT, propylpyrazole-triol; IL, Interleukin; IFN- $\gamma$, Interferongamma; TNF- $\alpha$, tumor necrosis factor- $\alpha$; CXCL1, chemokine (C-X-C motif) ligand 1; GM-CSF, Granulocyte-macrophage colony-stimulating factor; VEGF, vascular endothelial growth factor 


\section{Hlppocampus}
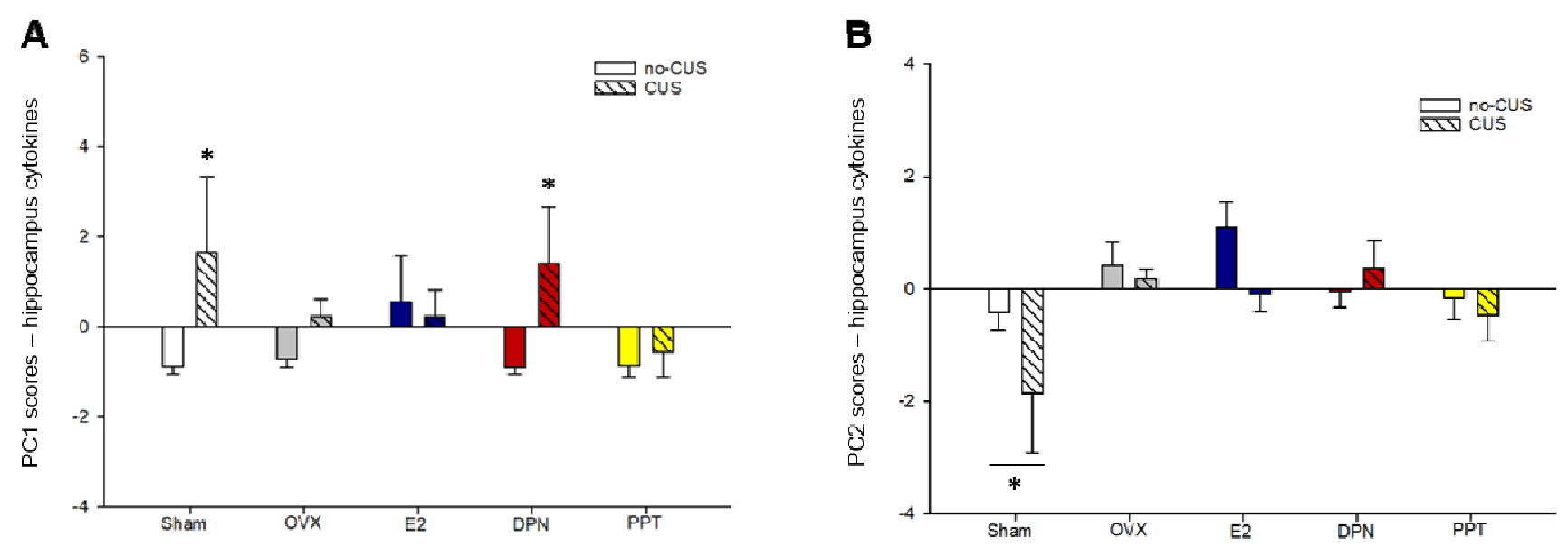

\section{Frontal cortex}
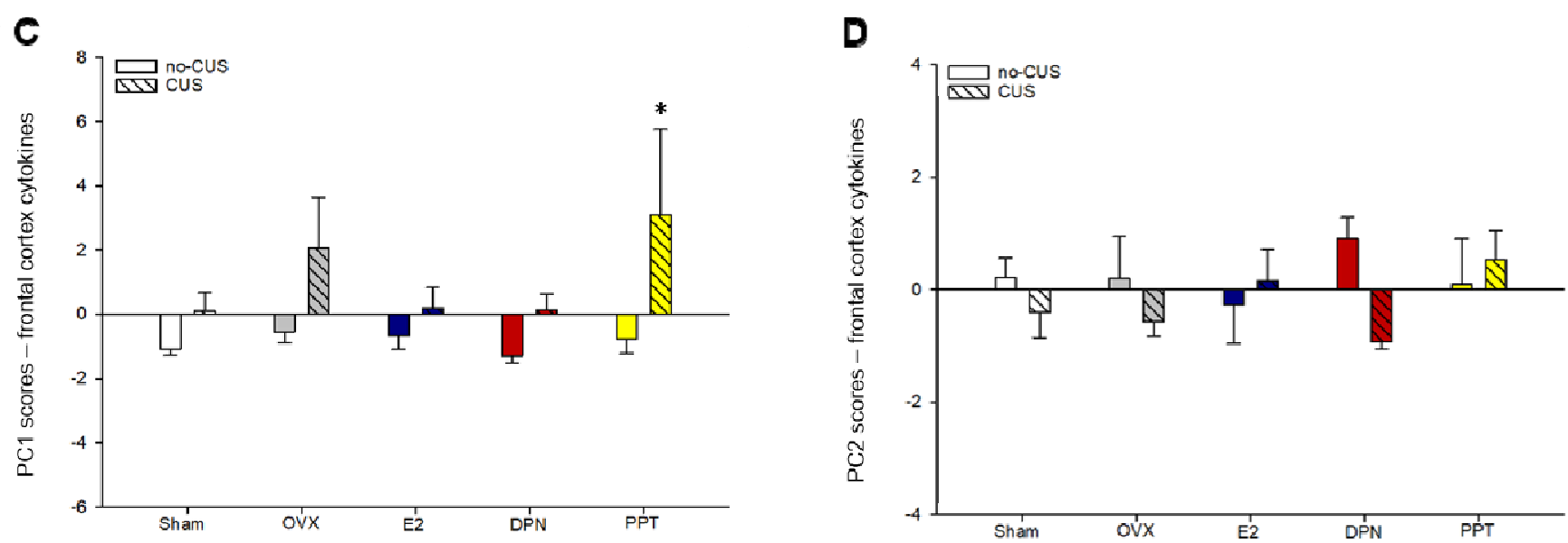

Figure 6. Principal component scores in hippocampus (A-B) and frontal cortex (C-D) analyses of cytokine data. (A) In the hippocampus, CUS exposure significantly increased principal component (PC) 1 scores, and this effect was driven by=Sham and DPN groups only; * indicate $\mathrm{p}<0.03$, relative to no-CUS counterparts. (B) Sham-operated groups had significantly lower PC2 scores in the hippocampus; * indicates p's $<0.02$, in comparison with all treatments except PPT $(\mathrm{p}=0.08)$. (C) In the frontal cortex, CUS exposure significantly increased PC1 scores, and this effect was driven by PPT treatment; * indicates $\mathrm{p}=0.003$ relative to no-CUS counterparts. (D) There were no significant group differences in frontal cortex PC2 scores. PC, principal component; CUS, chronic unpredictable stress; OVX, ovariectomized; E2, estradiol; DPN, diarylpropionitrile; PPT, propylpyrazole-triol. Data in means + standard error of the mean.

\section{Individual cytokine results: CUS increased several cytokines in the hippocampus and frontal} cortex, but the effects of estrogens were limited to VGEF and CXCL1 in the hippocampus

In the hippocampus, CUS exposure significantly increased TNF- $\alpha$, IL-1 $\beta$, and IL-10 concentrations (main effects of CUS: $F(1,53)=6.84, p=0.012, \eta^{2}=0.11 ; F(1,51)=12.87, p=0.0007, \eta^{2}{ }_{p}=0.20$; and $F(1$, 
53) $=7.38, \mathrm{p}=0.0009, \eta_{\mathrm{p}}^{2}=0.12$, respectively; Fig. 7A-C), but decreased CXCL1 concentrations $(\mathrm{F}(1$, 52) $=4.01$, p=0.05; Fig. 7D). However, IL-2, IL-4, IL-6, IFN- $\gamma$, VGEF, and GM-CSF were not significantly affected by CUS exposure (p's $>0.16$ ). Estrogens only significantly influenced two proteins: VEGF and CXCL1. Specifically, the ER $\beta$ agonist, DPN, increased hippocampal VEGF concentration relative to Sham and PPT groups (p's <0.03; main effect of treatment: $F(4,53)=3.55$, $\mathrm{p}=0.012, \eta_{\mathrm{p}}^{2}=0.21$; Fig. 7E), and E2 significantly increased hippocampal CXCL1 concentrations relative to Sham mice $\left(p=0.0045\right.$; main effect of treatment: $F(4,52)=3.57, p=0.012, \eta^{2}=0.22$; Fig. 7D). There were no other significant main or interaction effects for any other cytokine in the hippocampus (p's >0.083; Table 5). Finally, there was a significant covariate effect of DEX to reduce IL-1 $\beta$, IL-6, IL-10, and TNF- $\alpha$ concentrations (p's<0.05) and trends toward significance to reduce IL-2 $(\mathrm{p}=0.051)$ and GM-CSF $(\mathrm{p}=0.07)$ concentrations. DEX was not a significant covariate for concentrations of IFN- $\gamma$, VGEF, CXCL1, IL-4 (p's >0.14).

In the frontal cortex, CUS exposure significantly increased TNF- $\alpha$, IL-10, IL-1 $\beta$, IL-2, IL-4, and IL-6 concentrations (main effects of CUS condition: $\mathrm{F}(1,48)=10.59, \mathrm{p}=0.0021, \eta_{\mathrm{p}}^{2}=0.18 ; \mathrm{F}(1,46)=4.00$, $\mathrm{p}=0.05, \eta_{\mathrm{p}}^{2}=0.08 ; \mathrm{F}(1,42)=15.63, \mathrm{p}=0.0003, \eta_{\mathrm{p}}^{2}=0.27 ; \mathrm{F}(1,44)=7.47, \mathrm{p}=0.009, \eta_{\mathrm{p}}^{2}=0.15 ; \mathrm{F}(1$, 46) $=4.79, \mathrm{p}=0.034, \eta_{\mathrm{p}}^{2}=0.09$; and $\mathrm{F}(1,44)=9.57, \mathrm{p}=0.0034, \eta_{\mathrm{p}}^{2}=0.18$, respectively; Fig. 7F-K). However, GM-CSF, IFN-g, VEGF, and CXCL1 concentrations were not significantly affected by CUS exposure (p's>0.09; Table 5). Estrogens did not significantly influence any cytokine in the frontal cortex (all p's >0.13), nor were there any significant CUS condition by treatment interactions for any cytokine (p's >0.055). Finally, there was a significant covariate effect of DEX to reduce IL-1 $\beta$, IL-6, and VGEF in the frontal cortex ( $\left.\mathrm{p}^{\prime}<0.02\right)$, and a trend toward significance for reduced TNF- $\alpha$ $(\mathrm{p}=0.065)$, but not for any other cytokine examined (p's >0.13). 
A

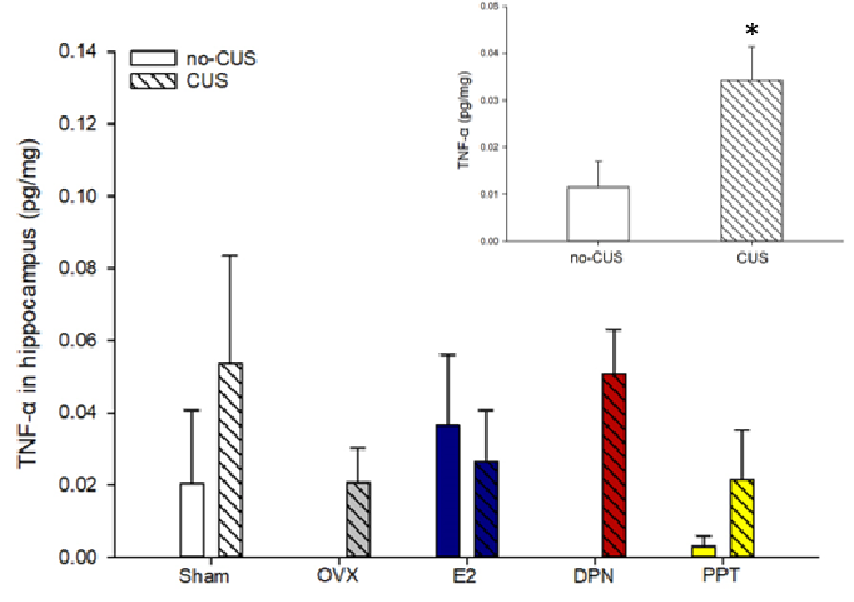

C

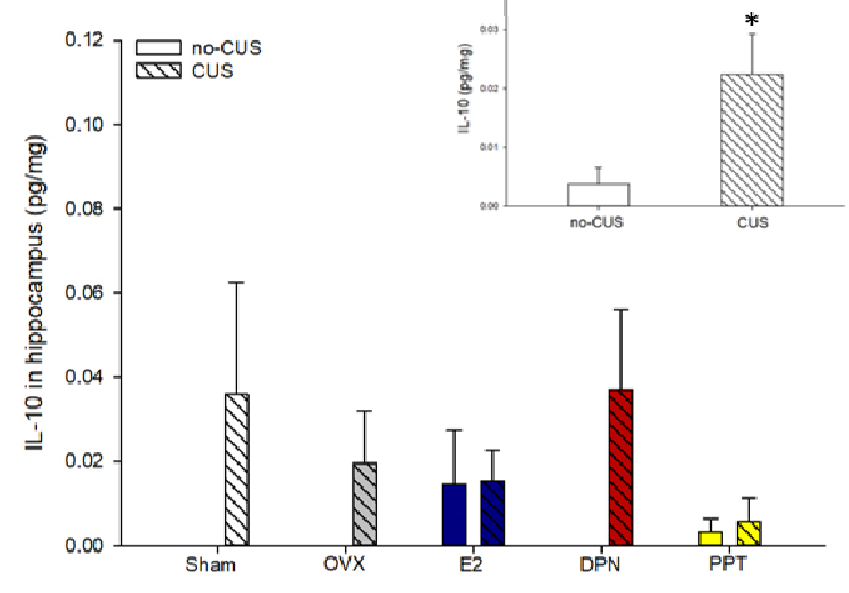

$\mathbf{E}$

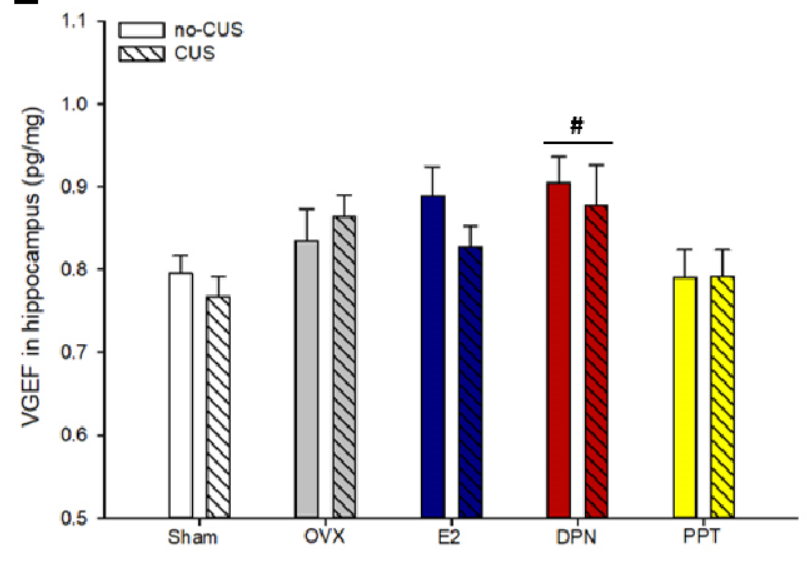

B

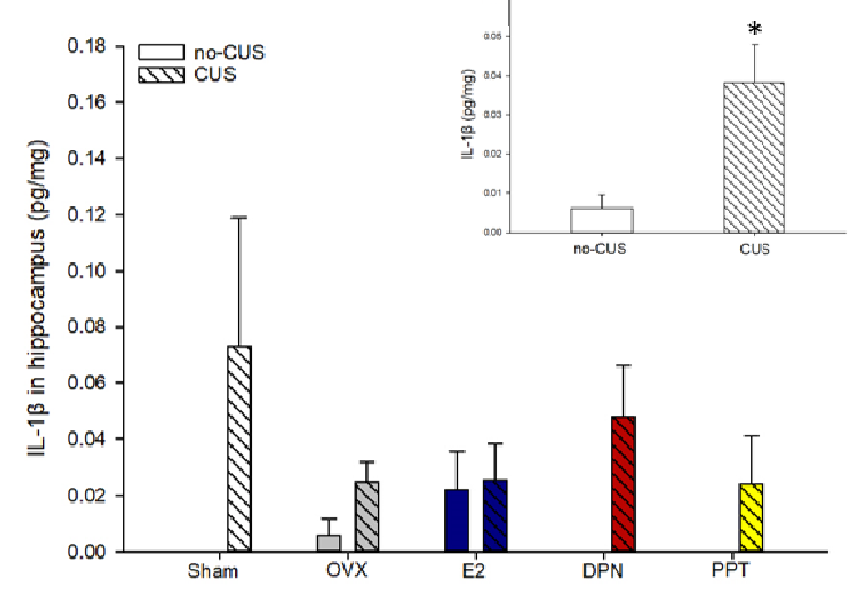

D

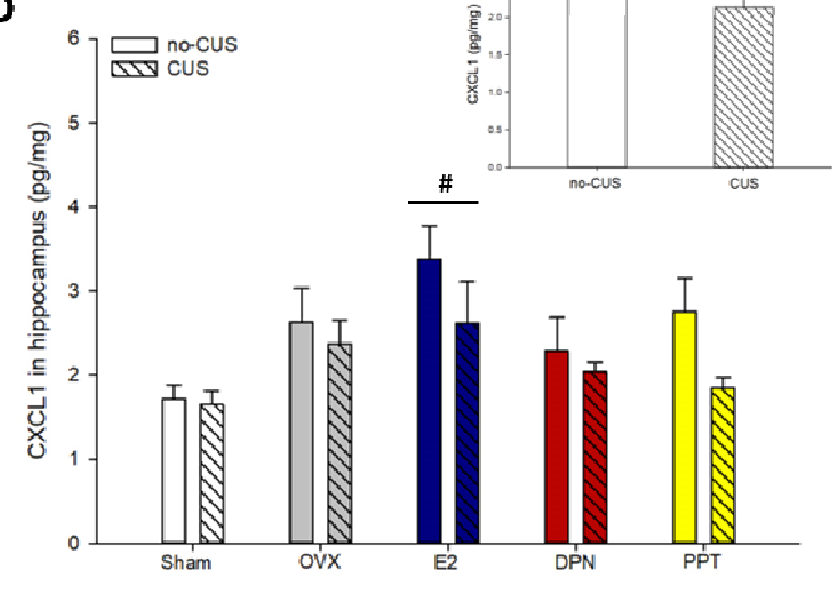




\section{Frontal Cortex}
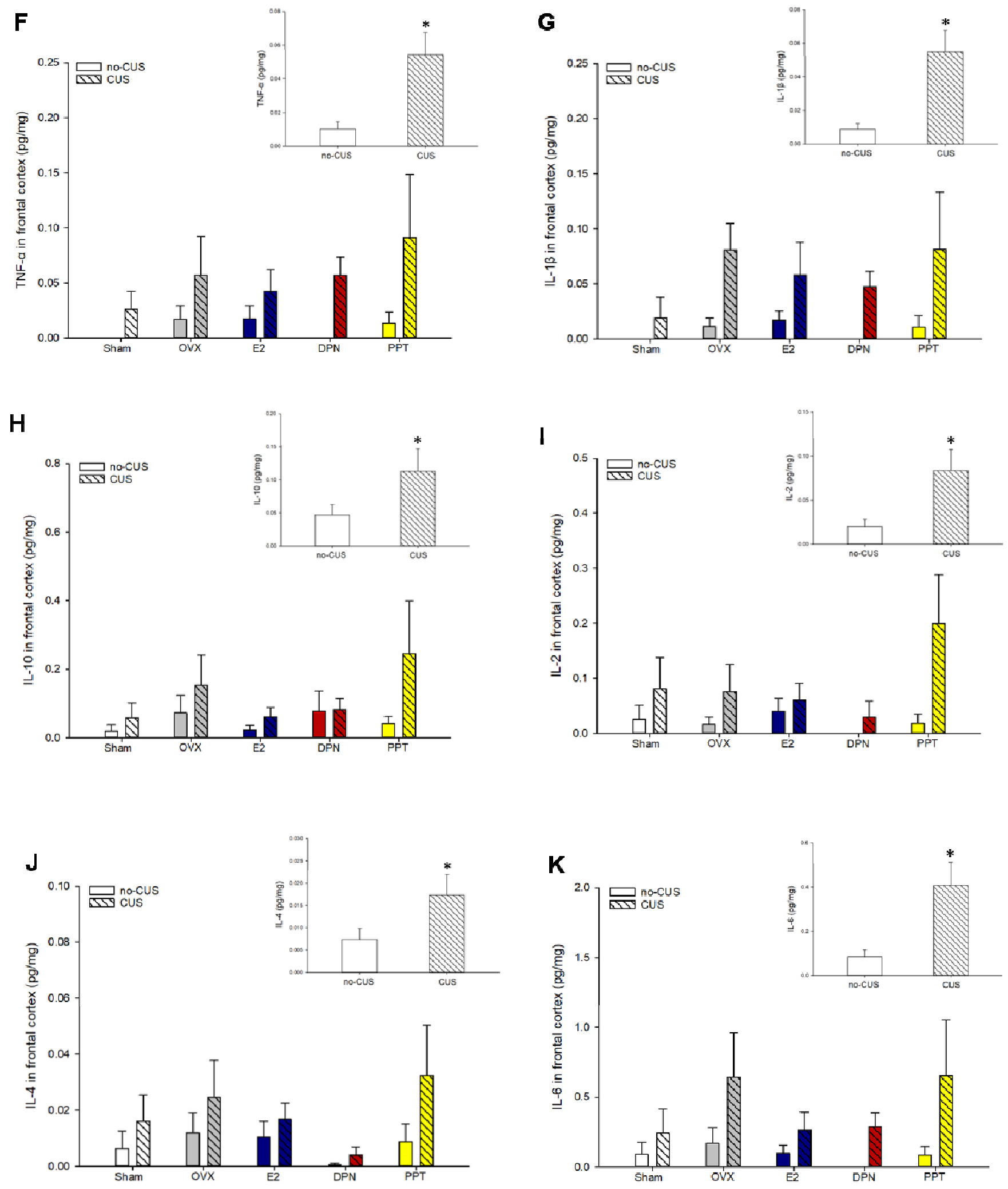
Figure 7. Protein concentrations of immune mediators in the hippocampus (A-E) and frontal cortex (F-K). CUS exposure increased TNF- $\alpha$ (A), IL-1 $\beta$ (B), and IL-10 (C) concentrations in the hippocampus; * indicates $p$ $<0.015$, main effect of CUS condition. (D) CUS exposure decreased and E2 treatment increased CXCL1 concentrations in the hippocampus; * indicates $\mathrm{p}=0.05$, main effect of CUS exposure, and \# indicates $\mathrm{p}=0045$ relative to Sham. (E) DPN treatment significantly increased VEGF concentrations in the hippocampus; * indicates $\mathrm{p}<0.03$, relative to Sham and PPT groups. CUS exposure increased TNF- $\alpha(\mathbf{F})$, IL-1 $\beta(\mathbf{G})$, IL-10 (H), IL-2 (I), IL-4 (J), and IL-6 (K) concentrations in the frontal cortex* indicates $p \leq 0.05$, main effect of CUS condition. IL, Interleukin; TNF- $\alpha$, tumor necrosis factor- $\alpha$; CXCL1, chemokine (C-X-C motif) ligand 1; VEGF, vascular endothelial growth factor; CUS, chronic unpredictable stress; OVX, ovariectomized; E2, estradiol; DPN, diarylpropionitrile; PPT, propylpyrazole-triol. Data in means + standard error of the mean.

Table 5. Protein concentrations (mean \pm standard error of the mean) of immune mediators in the hippocampus and frontal cortex, normalised to total protein concentrations ( $\mathrm{pg} / \mathrm{mg}$ ). No significant group differences were observed.

\begin{tabular}{|c|c|c|c|c|c|c|c|c|c|}
\hline \multirow[b]{2}{*}{ Group } & \multicolumn{5}{|c|}{ Hippocampus } & \multicolumn{4}{|c|}{ Frontal cortex } \\
\hline & GM-CSF & IFN-Y & IL-2 & IL-4 & IL-6 & GM-CSF & IFN-Y & CXCL1 & VEGF \\
\hline \multicolumn{10}{|c|}{ no-CUS } \\
\hline Sham & $\begin{array}{l}0.014 \pm \\
0.0017\end{array}$ & ND & ND & $\begin{array}{l}0.0029 \pm \\
0.0029\end{array}$ & $\begin{array}{l}0.17 \pm \\
0.14\end{array}$ & $\begin{array}{l}0.022 \pm \\
0.005\end{array}$ & ND & $\begin{array}{l}1.37 \pm \\
0.10\end{array}$ & $\begin{array}{l}1.02 \pm \\
0.05\end{array}$ \\
\hline OVX & $\begin{array}{l}0.015 \pm \\
0.0011\end{array}$ & ND & ND & $\begin{array}{l}0.0066 \pm \\
0.0047\end{array}$ & $\begin{array}{l}0.29 \pm \\
0.18\end{array}$ & $\begin{array}{l}0.023 \pm \\
0.006\end{array}$ & ND & $\begin{array}{l}1.99 \pm \\
0.64\end{array}$ & $\begin{array}{l}0.89 \pm \\
0.10\end{array}$ \\
\hline E2 & $\begin{array}{l}0.014 \pm \\
0.0008\end{array}$ & $\begin{array}{l}0.0008 \pm \\
0.0008\end{array}$ & $\begin{array}{l}0.0095 \pm \\
0.0095\end{array}$ & $\begin{array}{l}0.0123 \pm \\
0.0047\end{array}$ & $\begin{array}{l}0.28 \pm \\
0.10 \\
\end{array}$ & $\begin{array}{l}0.016 \pm \\
0.005\end{array}$ & $\begin{array}{l}0.0002 \pm \\
0.0002\end{array}$ & $\begin{array}{l}2.18 \pm \\
0.39 \\
\end{array}$ & $\begin{array}{l}0.82 \pm \\
0.15\end{array}$ \\
\hline DPN & $\begin{array}{l}0.016 \pm \\
0.0012\end{array}$ & ND & $\begin{array}{l}0.0176 \pm \\
0.0176\end{array}$ & ND & $\begin{array}{l}0.06 \pm \\
0.03 \\
\end{array}$ & $\begin{array}{l}0.030 \pm \\
0.006\end{array}$ & ND & $\begin{array}{l}2.34 \pm \\
0.67 \\
\end{array}$ & $\begin{array}{l}1.12 \pm \\
0.03\end{array}$ \\
\hline PPT & $\begin{array}{l}0.013 \pm \\
0.0011\end{array}$ & ND & $\begin{array}{l}0.0265 \pm \\
0.0193\end{array}$ & $\begin{array}{l}0.0036 \pm \\
0.0025\end{array}$ & $\begin{array}{l}0.12 \pm \\
0.06\end{array}$ & $\begin{array}{l}0.019 \pm \\
0.004\end{array}$ & ND & $\begin{array}{l}2.33 \pm \\
0.62 \\
\end{array}$ & $\begin{array}{l}0.87 \pm \\
0.13 \\
\end{array}$ \\
\hline \multicolumn{10}{|l|}{ CUS } \\
\hline Sham & $\begin{array}{l}0.017 \pm \\
0.0024\end{array}$ & ND & $\begin{array}{l}0.0970 \pm \\
0.0706\end{array}$ & $\begin{array}{l}0.0112 \pm \\
0.0051\end{array}$ & $\begin{array}{l}0.19 \pm \\
0.14\end{array}$ & $\begin{array}{l}0.020 \\
\pm 0.004\end{array}$ & $\begin{array}{l}0.0008 \pm \\
0.0008\end{array}$ & $\begin{array}{l}1.09 \pm \\
0.09\end{array}$ & $\begin{array}{l}0.82 \pm \\
0.05\end{array}$ \\
\hline OVX & $\begin{array}{l}0.014 \pm \\
0.0015 \\
\end{array}$ & ND & $\begin{array}{l}0.0068 \pm \\
0.0068\end{array}$ & $\begin{array}{l}0.0103 \pm \\
0.0048\end{array}$ & $\begin{array}{l}0.50 \pm \\
0.23 \\
\end{array}$ & $\begin{array}{l}0.021 \\
\pm 0.004 \\
\end{array}$ & $\begin{array}{l}0.0002 \pm \\
0.0002\end{array}$ & $\begin{array}{l}1.47 \pm \\
0.28 \\
\end{array}$ & $\begin{array}{l}0.94 \pm \\
0.10 \\
\end{array}$ \\
\hline E2 & $\begin{array}{l}0.015 \pm \\
0.0025\end{array}$ & ND & $\begin{array}{l}0.0345 \pm \\
0.0227 \\
\end{array}$ & $\begin{array}{l}0.0097 \pm \\
0.0055\end{array}$ & $\begin{array}{l}0.25 \pm \\
0.13 \\
\end{array}$ & $\begin{array}{l}0.017 \\
\pm 0.003 \\
\end{array}$ & $\begin{array}{l}0.0002 \pm \\
0.0002 \\
\end{array}$ & $\begin{array}{l}2.46 \pm \\
0.79 \\
\end{array}$ & $\begin{array}{l}0.95 \pm \\
0.08\end{array}$ \\
\hline DPN & $\begin{array}{l}0.014 \pm \\
0.0022\end{array}$ & $\begin{array}{l}0.0012 \pm \\
0.0008\end{array}$ & $\begin{array}{l}0.0114 \pm \\
0.0114\end{array}$ & $\begin{array}{l}0.0127 \pm \\
0.0089\end{array}$ & $\begin{array}{l}0.34 \pm \\
0.10 \\
\end{array}$ & $\begin{array}{l}0.015 \\
\pm 0.002\end{array}$ & ND & $\begin{array}{l}1.15 \pm \\
0.13 \\
\end{array}$ & $\begin{array}{l}0.81 \pm \\
0.04\end{array}$ \\
\hline PPT & $\begin{array}{l}0.013 \pm \\
0.0024\end{array}$ & $\begin{array}{l}0.0002 \pm \\
0.0002\end{array}$ & ND & $\begin{array}{l}0.0038 \pm \\
0.0038\end{array}$ & $\begin{array}{l}0.13 \pm \\
0.13\end{array}$ & $\begin{array}{l}0.027 \pm \\
0.006\end{array}$ & $\begin{array}{l}0.0044 \pm \\
0.0037\end{array}$ & $\begin{array}{l}1.30 \pm \\
0.08\end{array}$ & $\begin{array}{l}0.87 \pm \\
0.07\end{array}$ \\
\hline
\end{tabular}

ND, non-detectable; CUS, chronic unpredictable stress; Sham, sham-operated; OVX, ovariectomized; E2, estradiol; DPN, diarylpropionitrile; PPT, propylpyrazole-triol; IL, Interleukin; IFN- $\gamma$, Interferon-gamma; CXCL1, chemokine (C-X-C motif) ligand 1; GM-CSF, Granulocyte-macrophage colony-stimulating factor; VEGF, vascular endothelial growth factor.

\section{DPN treatment increased Iba-1 optical density in the dorsal GCL}

Irrespective of CUS condition, DPN treatment increased Iba-1 optical density in the dorsal GCL in comparison to OVX and E2-treated mice (p's <0.05; main effect of treatment: $F(4,53)=2.98, \mathrm{p}=0.027$, $\eta_{\mathrm{p}}^{2}=0.18$; Fig. 8). There were no group differences in Iba-1 optical density in the ventral GCL, ILmPFC, or PL-mPFC (all p's >0.2; no significant main effects or interactions; Table 6). 

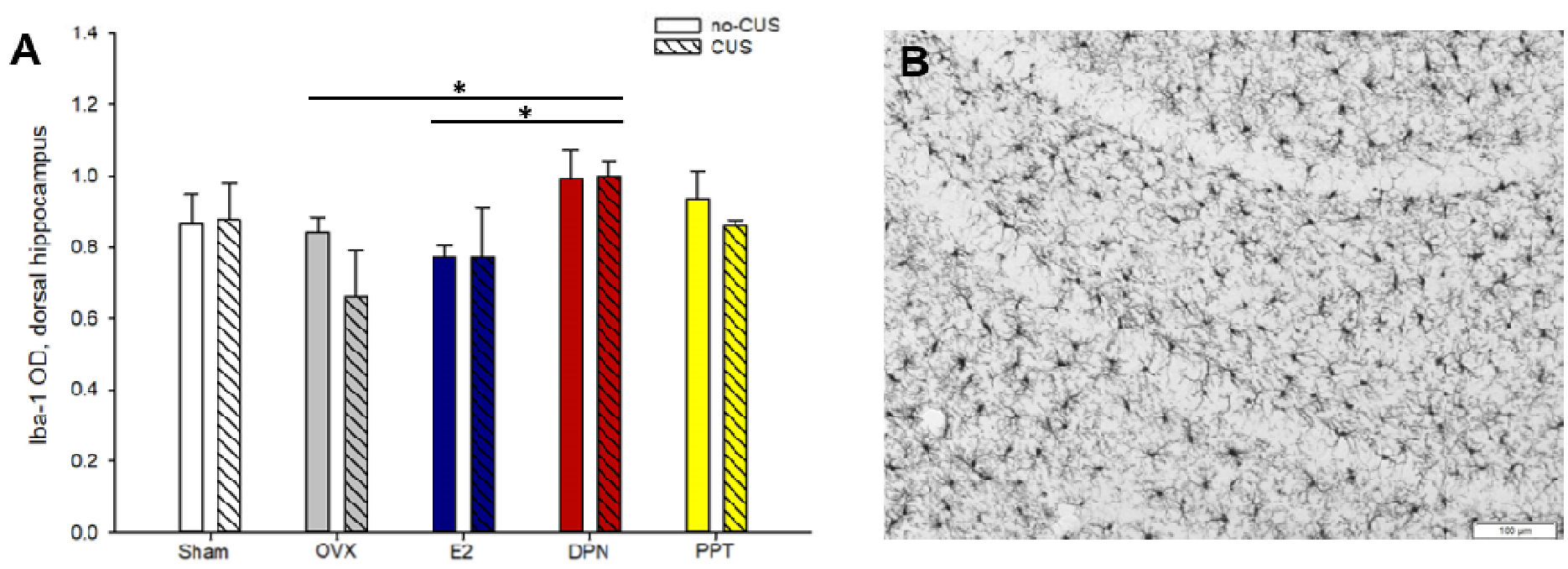

Figure 8. Iba-1 optical density in the dorsal dentate gyrus. (A) DPN treatment increased Iba-1 optical density in the granule cell layer of the dorsal dentate gyrus, irrespective of CUS exposure; * indicates p's $<0.05$, significantly higher than OVX and E2 groups. (B) representative photomicrograph of the dentate gyrus obtained at 10x magnification showing Iba-1-immunoreactive cells. OD, optical density; CUS, chronic unpredictable stress; OVX, ovariectomized; E2, estradiol; DPN, diarylpropionitrile; PPT, propylpyrazole-triol. Data in means + standard error of the mean.

Table 6. Iba-1 optical density (mean \pm standard error of the mean) in the ventral dentate gyrus and ventromedial prefrontal cortex. No significant group differences were observed.

\begin{tabular}{l|lll}
\hline \multicolumn{1}{c|}{ Group } & VDG & PL vmPFC & IL vmPFC \\
\hline no-CUS & & & \\
\hline Sham & $0.49 \pm 0.02$ & $0.74 \pm 0.04$ & $0.75 \pm 0.05$ \\
\hline OVX & $0.45 \pm 0.02$ & $0.71 \pm 0.03$ & $0.74 \pm 0.04$ \\
\hline E2 & $0.51 \pm 0.03$ & $0.74 \pm 0.02$ & $0.74 \pm 0.02$ \\
\hline DPN & $0.47 \pm 0.05$ & $0.75 \pm 0.03$ & $0.80 \pm 0.02$ \\
\hline PPT & $0.45 \pm 0.04$ & $0.71 \pm 0.04$ & $0.73 \pm 0.05$ \\
\hline CUS & & & $0.78 \pm 0.02$ \\
\hline Sham & $0.51 \pm 0.02$ & $0.77 \pm 0.02$ & $0.69 \pm 0.03$ \\
\hline OVX & $0.48 \pm 0.02$ & $0.72 \pm 0.03$ & $0.77 \pm 0.06$ \\
\hline E2 & $0.47 \pm 0.03$ & $0.74 \pm 0.03$ & $0.76 \pm 0.03$ \\
\hline DPN & $0.53 \pm 0.02$ & $0.73 \pm 0.04$ & $0.81 \pm 0.06$ \\
\hline PPT & $0.43 \pm 0.01$ & $0.81 \pm 0.06$ & \\
\hline
\end{tabular}

CUS, chronic unpredictable stress; Sham, sham-operated; OVX, ovariectomized; E2, estradiol; DPN, diarylpropionitrile; PPT, propylpyrazole-triol; vDG, ventral dentate gyrus; vmPFC, ventromedial prefrontal cortex; PL, prelimbic; IL, infralimbic 


\section{Discussion}

This study employed a pharmacological approach to investigate the role of the classical estrogen receptors, $\mathrm{ER} \alpha$ and $\mathrm{ER} \beta$, in the behavioural, neuroplastic and neuroinflammatory consequences of chronic stress exposure in female mice. CUS exposure increased immobility in the TST, increased concentrations of neuroinflammatory mediators, reduced PSD95 expression, and reduced neurogenesis in the ventral hippocampus. The effects of ovarian status and estrogenic treatments were overall less robust than those of CUS. We do, however, observe interesting effects of estrogenic treatments that in some instances depended on CUS exposure. We found that irrespective of CUS exposure, ovarian hormone deprivation increased passive-coping behaviour in the tail suspension test in comparison with sham-operated mice. Intriguingly, E2, DPN, and PPT treatments rescued this depressive-like outcome of ovariectomy under non-CUS conditions, but the effect of CUS exposure to increase depressive-like behaviour was primarily driven by the same treatments. On the other hand, ovarian hormone deprivation produced an anxiolytic effect in the novelty suppressed feeding test regardless of CUS exposure, and this was prevented by estradiol, but not DPN or PPT treatment. Further, the overall effects of CUS to alter the cytokine milieu and to reduce PSD-95 expression in the hippocampus and frontal cortex appear to be driven, at least in part, by DPN and PPT treatments, respectively. Finally, we observed a dorsal hippocampus-restricted effect of estradiol to increase neurogenesis. Combined, these findings shed light on the complexities of estrogen signaling in modulating behavioural, neuroplastic, and neuroinflammatory states under non-stress and chronic stress conditions. These findings further suggest that contrary to our expectations, chronic selective activation of ER $\alpha$ or $\beta$ does not impart resilience in the face of CUS exposure. These findings could have implications for the development of selective estrogen-based therapies for stress-related disorders.

\section{Ovarian status and estrogenic treatments produce distinct behavioural profiles depending on CUS condition and behavioural test}

Irrespective of CUS condition, ovariectomy increased passive-coping behaviour in the tail suspension test, and under non-CUS conditions, this effect was prevented by E2, DPN, and PPT treatments. This finding is consistent with previous reports showing that ovarian hormone deprivation alone increases depressive-like behaviour in both rats and mice, at least in the short term (Bekku and Yoshimura, 2005; Li et al., 2014). Importantly, our findings implicate both $\operatorname{ER} \alpha$ and $\beta$ in mediating the effects of estradiol to promote active-coping behaviour under non-stress conditions. This counters the findings of past studies that have administered ER agonists acutely to suggest a role of ER $\beta$, but not ER $\alpha$, in depressive-like behaviour under non-stress conditions (Walf et al., 2004; Yang et al., 2014). This 
contradictory finding is important, as acute treatments with ER agonists provide only limited information regarding the role of ERs in affective behaviour. Interestingly, although CUS exposure did not significantly affect passive-coping behaviour in the TST in sham-operated and ovariectomized mice, we report that CUS significantly increased passive-coping behaviour in DPN- and PPT-treated mice, with trends in the same direction with E2 treatment. This is somewhat in line with our analysis of resilience versus susceptibility to a depressive-like phenotype in TST, in which CUS exposure resulted in a resilient phenotype in the Sham group but a susceptible phenotype in OVX and PPT-treated groups, while no bias was observed in E2- or DPN-treated groups. This suggests that chronic, selective activation of $\mathrm{ER} \alpha$ or $\mathrm{ER} \beta$, is protective under non-stress conditions but not under CUS exposure. This seemingly contradictory finding could perhaps be interpreted in light of the "healthy cell bias of estrogen action" hypothesis (Brinton, 2008), put forth to explain observations in which the actions of estrogens result in disparate outcomes in health versus pathology. That is, under "healthy", non-stress conditions, estradiol and ER agonists protect against ovariectomy-induced depressive-like behaviour, yet under "pathological" chronic stress conditions the same treatments were not protective. A "pathological" state under chronic stress conditions could be related to consequences of increased HPA axis activity, including increased concentrations of corticotropin-releasing hormone $(\mathrm{CRH})$ and corticosterone. This finding is important as it underscores the need for using a model of depression when investigating estrogens' regulation of affective function.

It is important to note that the effects observed in the TST were not consistent across the entire battery of behavioural tests used in this study. For example, we do not see significant group differences in the forced swim test or the sucrose preference test. It is plausible that testing order could affect behaviour on subsequent tests, an issue that can be addressed by counterbalancing testing order in future studies. Further, unlike the observed effect of ovariectomy to increase passive-coping behaviour in the TST, we found an anxiolytic effect of ovariectomy in the novelty suppressed feeding test. This was seen irrespective of CUS exposure, and was prevented by E2, but not DPN or PPT treatment. This indicates that targeting $\operatorname{ER} \alpha$ or $\operatorname{ER} \beta$ alone was not sufficient to return anxiety-like behaviour to levels similar to that of intact mice. On the other hand, E2 treatment mimicked the phenotype of intact mice, indicating that concurrent activation of both receptor subtypes or possibly the $G$ protein coupled estrogen receptor 1 (GPER) may be involved in this response. In line with our current findings, estradiol benzoate treatment in ovariectomized C57BL/6 or Swiss Webster mice, administered chronically via subcutaneous capsule, increased anxiety-like behaviour in comparison to vehicle treatment across several tests of anxiety-like behaviour (Morgan and Pfaff, 2002, 2001). However, 
more studies find anxiogenic effects of ovariectomy and anxiolytic effects of acute, sub-chronic, or chronic estradiol treatment in ovariectomized rats or mice (Kastenberger et al., 2012; Walf et al., 2009b; Walf and Frye, 2010). Further, reduced anxiety-like behaviour is observed in proestrus, during which endogenous 17 $\beta$-estradiol is elevated (Frye et al., 2000; Walf et al., 2009a). Importantly, few studies have investigated the effects of ovarian hormones in the novelty suppressed feeding test, which targets motivated behaviour in addition to anxiety-like behaviour. In middle aged rats, we previously found increased anxiety like-behaviour in NSF with long-term ovariectomy and chronic stress exposure (Mahmoud et al., 2016). Another study in young adult rats found no effect of ovariectomy or chronic estradiol treatment (18 days) on behaviour in NSF (Gogos et al., 2018). It is therefore difficult to synthesize the existing literature, but it appears that length of ovarian hormone deprivation, estradiol dose and treatment regimen, species, strain, age, and test of anxiety-like behaviour can all contribute to the differences in findings.

In this study we investigate the corticosterone response to an acute stressor with and without a dexamethasone challenge (discussed ahead), but we did not explore changes in baseline HPA activity across the experimental timeline. Thus, in order to clarify the complexities and inconsistencies in the literature surrounding the role of ovarian hormones in anxiety- and depressive-like behaviour, it would be important to consider changes $\mathrm{CRH}$ and corticosterone as a result of ovariectomy and estrogenic treatments under both non-stress and chronic stress conditions. These hormones are regulated by estrogens (Goel et al., 2014; Oyola and Handa, 2017) and are key effectors of the primary neuroendocrine stress response system with notable effects on anxiety- and depressive-like behaviours, and known perturbations in MDD (Binder and Nemeroff, 2010; Stetler and Miller, 2011).

\section{Ovarian status and ER agonists influenced the neuroinflammatory consequences of CUS exposure in a brain region-specific manner}

The neuroinflammatory effects of chronic stress exposure are well documented in males (Kreisel et al., 2014; Kubera et al., 2011). Here, we also observe robust neuroinflammatory effects of CUS exposure in the frontal cortex and hippocampus in young adult female mice. Notably CUS increased concentrations of IL-1 $\beta$, IL- 6 and TNF- $\alpha$. This mirrors meta-analyses indicating increased concentrations of the same cytokines in the blood and cerebral spinal fluid of individuals with MDD (Dowlati et al., 2010; Haapakoski et al., 2015; Liu et al., 2012; Wang and Miller, 2018). We also demonstrate that ovarian status and selective ER activation can influence the neuroinflammatory response to stress in a brain region-dependent manner. Specifically, PCA analyses indicate that the neuroinflammatory effects of CUS were driven by PPT-treated groups in the frontal cortex, and by 
Sham and DPN-treated groups in the hippocampus. This suggests that chronic ER $\alpha$ and ER $\beta$ activation potentiated the neuroinflammatory consequences of stress exposure in the frontal cortex and hippocampus, respectively. This regional specificity also agrees with our observed effects of the ER $\beta$ agonist DPN to increase Iba-1 optical density in the dorsal dentate gyrus. It is possible that the exaggerated neuroinflammatory response to CUS in DPN and PPT groups could contribute to the enhanced behavioural susceptibility to CUS in the tail suspension test, however the current experiment cannot confirm this link. Previous studies provide support for a role of ER $\alpha$ and ER $\beta$ in the antiinflammatory and neuroprotective actions of estradiol (Brown et al., 2010; Chakrabarti et al., 2014; Lewis et al., 2008; Smith et al., 2011), however these conclusions are largely derived from studies using acute inflammatory challenges in vivo or from in vitro studies. Therefore, our current findings provide insight into the immunomodulatory actions of estradiol in the context of chronic stress exposure. Although estrogens themselves possess immunomodulatory actions, future studies should also consider how estrogens may influence the neuroinflammatory milieu indirectly via the regulation of the HPA axis, especially under conditions of chronic stress. This is important as CRH can produce anti-inflammatory effects indirectly via the actions of glucocorticoids, but can also can directly produce pro-inflammatory effects (Bellavance and Rivest, 2014; Bereshchenko et al., 2018; Elenkov et al., 1999). Therefore, considering well known HPA-HPG interactions (Goel et al., 2014) may shed light on how differing backgrounds of ovarian hormones can influence the neuroinflammatory consequences of stress exposure.

\section{7ß-estradiol increased neurogenesis in the dorsal hippocampus}

Chronic 17 $\beta$-estradiol treatment increased the number of BrdU-ir cells in the dorsal dentate gyrus and increased the proportion of BrdU-ir cells that also expressed the mature neuronal marker (NeuN). This finding is interesting considering the functional heterogeneity along the dorsal-ventral axis of the hippocampus, in which the dorsal region is predominantly implicated in cognitive function (Fanselow and Dong, 2010; Strange et al., 2014). Few studies to date have examined the effects of chronic 17 $\beta$ estradiol treatment in ovariectomized females on the survival of new neurons in the hippocampus, but the available evidence indicates that the effects depend on the timing of $17 \beta$-estradiol exposure in relation to that of cell proliferation. The survival of new neurons was found to be increased in cell populations that had proliferated after the initiation of estradiol treatment (McClure et al., 2013), but reduced in cell populations that proliferated prior to the initiation of estradiol treatment (Barker and Galea, 2008; Chan et al., 2014). Our current data corroborate this past literature, as 17 $\beta$-estradiol treatment here was initiated two weeks prior to BrdU administration. Therefore, our current findings 
provide further support for the notion that a $17 \beta$-estradiol rich vs deficient environment during cell proliferation can largely influence the effects of chronic $17 \beta$-estradiol treatment on the survival of new neurons. Further, as several studies report pro-proliferative effects of $17 \beta$-estradiol that depend on dose and timing of treatment (Barha et al., 2009; Ormerod and Galea, 2001; Tanapat et al., 2005, 1999), the effect of E2 to increase BrdU-ir cells in the current study could be attributed to increased cell proliferation. To our knowledge, the effects $\operatorname{ER} \alpha$ and $\beta$ agonists on hippocampal cell survival have not been investigated prior to this study. We found that unlike E2 treatment, DPN and PPT did not increase neurogenesis in the dorsal dentate gyrus, despite previous data showing that acute administration of DPN or PPT enhances cell proliferation, albeit at a different dose (Mazzucco et al., 2006). Therefore, promoting the survival of cells proliferating in an estradiol rich environment may require the concurrent engagement of ER $\alpha$ and $\beta$ or alternatively GPER, which is achieved by estradiol but not PPT or DPN. It is important to note that although NeuN remains to be the gold standard for identifying neuronal fate of adult born granule cells, NeuN immunoreactivity and antibody binding can differ between neurons in other brain regions and is influenced by a variety of factors including protein phosphorylation (Gusel'nikova and Korzhevskiy, 2015; Lind et al., 2005). Thus, the possibility exists that hormonal treatments in this study may have affected NeuN immunoreactivity and colocalization with BrdU without having any significant change in neuronal number. However, in unpublished observations we did not detect any change in NeuN intensity between groups.

\section{CUS exposure reduced markers of neuroplasticity (PSD-95 expression and neurogenesis)}

CUS significantly reduced neurogenesis in the ventral, but not dorsal, hippocampus, and impacted cell fate by reducing the proportion of new cells becoming neurons. This is in line with the finding that neurogenesis in this region promotes stress resilience in males (Anacker et al., 2018) and with an overall role of the ventral hippocampus in stress regulation (Bagot et al., 2015; Fanselow and Dong, 2010; Padilla-Coreano et al., 2016). We also observe an overall effect of CUS to reduce PSD-95 in both the hippocampus and frontal cortex, pointing to a reduction in excitatory synapse number and/or stability. Importantly, this parallels findings of reduced expression of PSD-95, synapse loss, and reduced expression of synapse-related genes in the PFC and hippocampus of individuals with MDD (Duric et al., 2013; Feyissa et al., 2009; Kang et al., 2012). Interestingly, CUS-induced reductions in PSD-95 expression were largely driven by DPN and PPT treated groups. This indicates that chronic DPN or PPT treatment in tandem with CUS exposure may result in remodeling of neuronal circuits in regions important for mood and stress regulation, and this could be linked to the observed behavioural alterations under CUS exposure in the tail suspension test. This effect may be driven by stress-induced 
alterations in the HPA axis, including possible elevations in basal levels of CRH and corticosterone, a possibility that should be explored in future studies. On the other hand, we found limited effects of estrogenic treatments on PSD-95 expression under non-CUS conditions. In contrast, previous studies report increased PSD-95 expression in the hippocampus of female rats after acute treatment with estradiol, PPT, and to a lesser extent DPN (Waters et al., 2009) and with $17 \beta$-estradiol treatment in vitro (Akama and McEwen, 2003), therefore the differences between these findings and our current observations are likely due to treatment duration.

\section{Chronic 17 $\beta$-estradiol treatment blunted the corticosterone response to an acute stressor and CUS exposure increased HPA axis negative feedback sensitivity}

Chronic 17 $\beta$-estradiol treatment, regardless of CUS exposure, blunted the corticosterone response to an acute restraint stressor. This partially contrasts previous studies which in general have indicated that ovarian hormones, and $17 \beta$-estradiol in particular, potentiate acute stress-induced activation of the HPA axis (Carey et al., 1995; Figueiredo et al., 2007; Serova et al., 2010). Importantly, most past studies have used shorter durations of estradiol replacement than in the current study, which likely contributes to the differences in findings. It is important to keep in mind that although the dose of $17 \beta$ estradiol used here produce proestrus-like circulating concentrations, the daily treatment regimen does not mimic natural estradiol cyclicity in the mouse, but rather is informative to potential effects of chronic estrogen-based therapies. Our current findings therefore extend the past literature to suggest that longer durations of $17 \beta$-estradiol replacement may suppress the HPA axis response to stressors, which could represent a protective effect.

Studies in humans generally report a failure of dexamethasone to suppress cortisol release in a subpopulation of individuals with MDD (Ising et al., 2007; Stetler and Miller, 2011), pointing to impaired HPA axis negative feedback inhibition. In the current study, however, we observed enhanced dexamethasone suppression of corticosterone in mice exposed to CUS, pointing to increased sensitivity of negative feedback inhibition. This effect was present in all treatment groups except for E2, however this could be explained by the above-mentioned suppression of corticosterone in response to acute restraint stress in absence of dexamethasone. This unexpected enhancement of negative feedback inhibition with CUS could be an adaptive response to prevent prolonged exposure to glucocorticoids under chronic stress conditions. Interestingly, a similar phenotype is reported in clinical populations of trauma exposure and post-traumatic stress disorder (PTSD), in individuals with comorbid MDD and PTSD (Griffin et al., 2005; Yehuda et al., 1993), and in women with atypical MDD (Levitan et al., 
2002), suggesting that this profile can be seen in certain stress-related psychiatric disorders, including MDD with atypical features, which is more prevalent in women than in men (Marcus et al., 2008).

\section{Conclusion:}

In conclusion, we observe depressive-like, neuroinflammatory, and neuroplastic effects of CUS in young adult female mice that were largely independent of ovarian status and estrogenic treatments. However, our findings also point to complex effects of ovariectomy and estradiol/ER agonist replacement that in some instances were dependent on chronic stress condition. Specifically, ovariectomy increased passive-coping behaviour in the tail suspension test regardless of CUS exposure, and this effect was rescued by estradiol and ER agonists only under non-CUS conditions, suggesting that active-coping behaviour is promoted by $\mathrm{ER} \alpha$ and $\mathrm{ER} \beta$. Intriguingly, the effects of CUS exposure to increase passive-coping behaviour in the TST were largely driven by the same treatments. In agreement with the increased behavioural susceptibility to CUS exposure, the effects of CUS to modify the cytokine milieu and reduced PSD-95 expression appear to be driven in part by DPN and PPT. In addition, although ovariectomy increased passive-coping behaviour in the TST, it reduced anxiety-like behaviour in the NSF test regardless of CUS exposure. This effect was only prevented by $17 \beta$-estradiol treatment suggesting that the concurrent activation of $\operatorname{ER} \alpha, \operatorname{ER} \beta$ and GPER produced an anxiogenic effect in this paradigm. We further observe opposing effects of estradiol and CUS exposure on BrdU-ir cell number along the dorsal-ventral axis of the hippocampus, such that $17 \beta$-estradiol increased and CUS decreased BrdU-ir cells in the dorsal and ventral regions, respectively. Finally, CUS exposure resulted in increased HPA axis negative feedback sensitivity in most groups, pointing to stress-induced adaptations in HPA axis function. Taken together, these data highlight that estrogenic regulation of behaviour, neuroplasticity, and neuroinflammation is complex and at times depends on chronic stress condition. Moreover, our data indicate that chronic selective activation of $\operatorname{ER} \alpha$ or ER $\beta$ is not protective under chronic stress exposure, which could have implications for the development of estrogen-based therapies for stress-related disorders such as depression.

\section{Funding}

This work was supported by a Canadian Institute of Health Research grant to LAMG (MOP 142308), and a Marshall Scholarship to RSE from the Institute of Mental Health at the University of British Columbia.

\section{Declarations of interest}

None. 


\section{References}

Akama, K.T., McEwen, B.S., 2003. Estrogen Stimulates Postsynaptic Density-95 Rapid Protein Synthesis via the Akt/Protein Kinase B Pathway. J. Neurosci. https://doi.org/10.1523/jneurosci.2306-02333.2003

Anacker, C., Luna, V.M., Stevens, G.S., Millette, A., Shores, R., Jimenez, J.C., Chen, B., Hen, R., 2018. Hippocampal neurogenesis confers stress resilience by inhibiting the ventral dentate gyrus. Nature. https://doi.org/10.1038/s41586-018-0262-4

Bagot, R.C., Parise, E.M., Peña, C.J., Zhang, H.X., Maze, I., Chaudhury, D., Persaud, B., Cachope, R., Bolaños-Guzmán, C.A., Cheer, J., Deisseroth, K., Han, M.H., Nestler, E.J., 2015. Ventral hippocampal afferents to the nucleus accumbens regulate susceptibility to depression. Nat. Commun. https://doi.org/10.1038/ncomms8062

Baker, A.E., Brautigam, V.M., Watters, J.J., 2004. Estrogen modulates microglial inflammatory mediator production via interactions with estrogen receptor $\beta$. Endocrinology 145, 5021-5032. https://doi.org/10.1210/en.2004-0619

Barha, C.K., Lieblich, S.E., Chow, C., Galea, L.A.M., 2015. Multiparity-induced enhancement of hippocampal neurogenesis and spatial memory depends on ovarian hormone status in middle age. Neurobiol. Aging 36, 2391-2405. https://doi.org/10.1016/j.neurobiolaging.2015.04.007

Barha, C.K., Lieblich, S.E., Galea, L.A.M., 2009. Different forms of oestrogen rapidly upregulate cell proliferation in the dentate gyrus of adult female rats. J. Neuroendocrinol. 21, 155-166. https://doi.org/10.1111/j.1365-2826.2008.01809.x

Beagley, K.W., Gockel, C.M., 2003. Regulation of innate and adaptive immunity by the female sex hormones oestradiol and progesterone. FEMS Immunol. Med. Microbiol. https://doi.org/10.1016/S0928-8244(03)00202-5

Bekku, N., Yoshimura, H., 2005. Animal model of menopausal depressive-like state in female mice: Prolongation of immobility time in the forced swimming test following ovariectomy. Psychopharmacology (Berl). https://doi.org/10.1007/s00213-005-0179-0

Bellavance, M.A., Rivest, S., 2014. The HPA - immune axis and the immunomodulatory actions of glucocorticoids in the brain. Front. Immunol. https://doi.org/10.3389/fimmu.2014.00136

Bereshchenko, O., Bruscoli, S., Riccardi, C., 2018. Glucocorticoids, sex hormones, and immunity. 
Front. Immunol. https://doi.org/10.3389/fimmu.2018.01332

Binder, E.B., Nemeroff, C.B., 2010. The CRF system, stress, depression and anxietyinsights from human genetic studies. Mol. Psychiatry. https://doi.org/10.1038/mp.2009.141

Björnström, L., Sjöberg, M., 2005. Mechanisms of Estrogen Receptor Signaling: Convergence of Genomic and Nongenomic Actions on Target Genes. Mol. Endocrinol. https://doi.org/10.1210/me.2004-0486

Bodnar, T.S., Taves, M.D., Lavigne, K.M., Woodward, T.S., Soma, K.K., Weinberg, J., 2017. Differential activation of endocrine-immune networks by arthritis challenge: Insights from colonyspecific responses. Sci. Rep. 7, 1-14. https://doi.org/10.1038/s41598-017-00652-4

Brechbuhl, J., Moine, F., Klaey, M., Nenniger-Tosato, M., Hurni, N., Sporkert, F., Giroud, C., Broillet, M.-C., 2013. Mouse alarm pheromone shares structural similarity with predator scents. Proc. Natl. Acad. Sci. https://doi.org/10.1073/pnas.1214249110

Brinton, R.D., 2009. Estrogen-induced plasticity from cells to circuits: predictions for cognitive function. Trends Pharmacol. Sci. https://doi.org/10.1016/j.tips.2008.12.006

Brinton, R.D., 2008. The healthy cell bias of estrogen action: mitochondrial bioenergetics and neurological implications. Trends Neurosci. https://doi.org/10.1016/j.tins.2008.07.003

Brown, C.M., Mulcahey, T.A., Filipek, N.C., Wise, P.M., 2010. Production of proinflammatory cytokines and chemokines during neuroinflammation: Novel roles for estrogen receptors $\alpha$ and $\beta$. Endocrinology. https://doi.org/10.1210/en.2010-0371

Can, A., Dao, D.T., Arad, M., Terrillion, C.E., Piantadosi, S.C., Gould, T.D., 2012. The mouse forced swim test. J. Vis. Exp. e3638. https://doi.org/10.3791/3638

Can, A., Dao, D.T., Terrillion, C.E., Piantadosi, S.C., Bhat, S., Gould, T.D., 2011. The Tail Suspension Test. J. Vis. Exp. https://doi.org/10.3791/3769

Carey, M.P., Deterd, C.H., De Koning, J., Helmerhorst, F., De Kloet, E.R., 1995. The influence of ovarian steroids on hypothalamic-pituitary-adrenal regulation in the female rat. J. Endocrinol.

Chakrabarti, M., Haque, A., Banik, N.L., Nagarkatti, P., Nagarkatti, M., Ray, S.K., 2014. Estrogen receptor agonists for attenuation of neuroinflammation and neurodegeneration. Brain Res. Bull. https://doi.org/10.1016/j.brainresbull.2014.09.004

Ciana, P., Raviscioni, M., Mussi, P., Vegeto, E., Que, I., Parker, M.G., Lowik, C., Maggi, A., 2003. In 
vivo imaging of transcriptionally active estrogen receptors. Nat. Med.

https://doi.org/10.1038/nm809

Clipperton, A.E., Spinato, J.M., Chernets, C., Pfaff, D.W., Choleris, E., 2008. Differential effects of estrogen receptor alpha and beta specific agonists on social learning of food preferences in female mice. Neuropsychopharmacology. https://doi.org/10.1038/sj.npp.1301625

Cohen, L.S., Soares, C.N., Vitonis, A.F., Otto, M.W., Harlow, B.L., 2006. Risk for New Onset of Depression During the Menopausal Transition The Harvard Study of Moods and Cycles. Arch Gen Psychiatry 63, 385-390. https://doi.org/10.1001/archpsyc.63.4.385

Cora, M.C., Kooistra, L., Travlos, G., 2015. Vaginal Cytology of the Laboratory Rat and Mouse:Review and Criteria for the Staging of the Estrous Cycle Using Stained Vaginal Smears. Toxicol. Pathol. 43, 776-793. https://doi.org/10.1177/0192623315570339

Dowlati, Y., Herrmann, N., Swardfager, W., Liu, H., Sham, L., Reim, E.K., Lanctôt, K.L., 2010. A Meta-Analysis of Cytokines in Major Depression. Biol. Psychiatry 67, 446-457. https://doi.org/10.1016/j.biopsych.2009.09.033

Duric, V., Banasr, M., Stockmeier, C.A., Simen, A.A., Newton, S.S., Overholser, J.C., Jurjus, G.J., Dieter, L., Duman, R.S., 2013. Altered expression of synapse and glutamate related genes in postmortem hippocampus of depressed subjects. Int. J. Neuropsychopharmacol. https://doi.org/10.1017/S1461145712000016

Eid, R.S., Chaiton, J.A., Lieblich, S.E., Bodnar, T.S., Weinberg, J., Galea, L.A.M., 2019a. Early and late effects of maternal experience on hippocampal neurogenesis, microglia, and the circulating cytokine milieu. Neurobiol. Aging 78, 1-17. https://doi.org/10.1016/j.neurobiolaging.2019.01.021

Eid, R.S., Gobinath, A.R., Galea, L.A.M., 2019b. Sex differences in depression: Insights from clinical and preclinical studies. Prog. Neurobiol. https://doi.org/10.1016/J.PNEUROBIO.2019.01.006

Elenkov, I.J., Webster, E.L., Torpy, D.J., Chrousos, G.P., 1999. Stress, corticotropin-releasing hormone, glucocorticoids, and the immune/inflammatory response: Acute and chronic effects, in: Annals of the New York Academy of Sciences. New York Academy of Sciences, pp. 1-13. https://doi.org/10.1111/j.1749-6632.1999.tb07618.x

Enache, D., Pariante, C., Mondelli, V., 2019. Markers of central inflammation in major depressive disorder: a systematic review and meta-analysis of studies examining cerebrospinal fluid, positron emission tomography and post-mortem brain tissue. Brain. Behav. Immun. 


\section{https://doi.org/10.1016/J.BBI.2019.06.015}

Fanselow, M.S., Dong, H.W., 2010. Are the Dorsal and Ventral Hippocampus Functionally Distinct

Structures? Neuron 65, 7-19. https://doi.org/10.1016/j.neuron.2009.11.031

Feyissa, A.M., Chandran, A., Stockmeier, C.A., Karolewicz, B., 2009. Reduced levels of NR2A and NR2B subunits of NMDA receptor and PSD-95 in the prefrontal cortex in major depression. Prog. Neuro-Psychopharmacology Biol. Psychiatry 33, 70-75.

https://doi.org/10.1016/j.pnpbp.2008.10.005

Figueiredo, H.F., Ulrich-Lai, Y.M., Choi, D.C., Herman, J.P., 2007. Estrogen potentiates adrenocortical responses to stress in female rats. Am. J. Physiol. Metab.

https://doi.org/10.1152/ajpendo.00102.2006

Frye, C.A., Petralia, S.M., Rhodes, M.E., 2000. Estrous cycle and sex differences in performance on anxiety tasks coincide with increases in hippocampal progesterone and $3 \alpha, 5 \alpha$-THP. Pharmacol. Biochem. Behav. https://doi.org/10.1016/S0091-3057(00)00392-0

Galea, L.A.M., Roes, M.M., Dimech, C.J., Chow, C., Mahmoud, R., Lieblich, S.E., Duarte-Guterman, P., 2018. Premarin has opposing effects on spatial learning, neural activation, and serum cytokine levels in middle-aged female rats depending on reproductive history. Neurobiol. Aging. https://doi.org/10.1016/j.neurobiolaging.2018.06.030

Goel, N., Workman, J.L., Lee, T.T., Innala, L., Viau, V., 2014. Sex differences in the HPA axis.

Compr. Physiol. 4, 1121-1155. https://doi.org/10.1002/cphy.c130054

Gogos, A., McCarthy, M., Walker, A.J., Udawela, M., Gibbons, A., Dean, B., Kusljic, S., 2018.

Differential effects of chronic $17 \beta$-oestradiol treatment on rat behaviours relevant to depression. J. Neuroendocrinol. https://doi.org/10.1111/jne.12652

Griffin, M.G., Resick, P.A., Yehuda, R., 2005. Enhanced cortisol suppression following dexamethasone administration in domestic violence survivors. Am. J. Psychiatry. https://doi.org/10.1176/appi.ajp.162.6.1192

Grossman, C.J., 1985. Interactions between the gonadal steroids and the immune system. Science (80-. ). https://doi.org/10.1126/science.3871252

Gusel'nikova, V. V., Korzhevskiy, D.E., 2015. NeuN as a neuronal nuclear antigen and neuron differentiation marker. Acta Naturae. https://doi.org/10.32607/20758251-2015-7-2-42-47

Haapakoski, R., Mathieu, J., Ebmeier, K.P., Alenius, H., Kivimäki, M., 2015. Cumulative meta- 
analysis of interleukins 6 and $1 \beta$, tumour necrosis factor $\alpha$ and C-reactive protein in patients with major depressive disorder. Brain. Behav. Immun. 49, 206-215.

https://doi.org/10.1016/j.bbi.2015.06.001

Harburger, L.L., Bennett, J.C., Frick, K.M., 2007. Effects of estrogen and progesterone on spatial memory consolidation in aged females. Neurobiol. Aging.

https://doi.org/10.1016/j.neurobiolaging.2006.02.019

Hendrick, V., Altshuler, L.L., Suri, R., 1998. Hormonal changes in the postpartum and implications for postpartum depression. Psychosomatics 39, 93-101. https://doi.org/10.1016/S0033-

3182(98)71355-6

Hodes, G.E., Kana, V., Menard, C., Merad, M., Russo, S.J., 2015. Neuroimmune mechanisms of depression. Nat. Neurosci. https://doi.org/10.1038/nn.4113

Ishihara, Y., Itoh, K., Ishida, A., Yamazaki, T., 2015. Selective estrogen-receptor modulators suppress microglial activation and neuronal cell death via an estrogen receptor-dependent pathway. J.

Steroid Biochem. Mol. Biol. https://doi.org/10.1016/j.jsbmb.2014.10.002

Ising, M., Horstmann, S., Kloiber, S., Lucae, S., Binder, E.B., Kern, N., Künzel, H.E., Pfennig, A., Uhr, M., Holsboer, F., 2007. Combined Dexamethasone/Corticotropin Releasing Hormone Test Predicts Treatment Response in Major Depression-A Potential Biomarker? Biol. Psychiatry 62, 47-54. https://doi.org/10.1016/j.biopsych.2006.07.039

Jolliffe, I.T., 2002. Principal Component Analysis, Second Edition. Encycl. Stat. Behav. Sci. https://doi.org/10.2307/1270093

Kallarackal, A.J., Kvarta, M.D., Cammarata, E., Jaberi, L., Cai, X., Bailey, A.M., Thompson, S.M., 2013. Chronic Stress Induces a Selective Decrease in AMPA Receptor-Mediated Synaptic Excitation at Hippocampal Temporoammonic-CA1 Synapses. J. Neurosci. https://doi.org/10.1523/JNEUROSCI.2588-13.2013

Kang, H.J., Voleti, B., Hajszan, T., Rajkowska, G., Stockmeier, C.A., Licznerski, P., Lepack, A., Majik, M.S., Jeong, L.S., Banasr, M., Son, H., Duman, R.S., 2012. Decreased expression of synapse-related genes and loss of synapses in major depressive disorder. Nat. Med. https://doi.org/10.1038/nm.2886

Kastenberger, I., Lutsch, C., Schwarzer, C., 2012. Activation of the G-protein-coupled receptor GPR30 induces anxiogenic effects in mice, similar to oestradiol. Psychopharmacol. 527-535. 
https://doi.org/10.1007/s00213-011-2599-3

Kempermann, G., Gage, F.H., Aigner, L., Song, H., Curtis, M.A., Thuret, S., Kuhn, H.G., Jessberger, S., Frankland, P.W., Cameron, H.A., Gould, E., Hen, R., Abrous, D.N., Toni, N., Schinder, A.F., Zhao, X., Lucassen, P.J., Frisén, J., 2018. Human Adult Neurogenesis: Evidence and Remaining Questions. Cell Stem Cell 23, 25-30. https://doi.org/10.1016/j.stem.2018.04.004

Kessler, R.C., Bromet, E.J., 2013. The epidemiology of depression across cultures. Annu. Rev. Public Health 34, 119-38. https://doi.org/10.1146/annurev-publhealth-031912-114409

Kim, D.M., Leem, Y.H., 2016. Chronic stress-induced memory deficits are reversed by regular exercise via AMPK-mediated BDNF induction. Neuroscience.

https://doi.org/10.1016/j.neuroscience.2016.03.019

Kim, E., Sheng, M., 2004. PDZ DOMAIN PROTEINS OF SYNAPSES. Nat. Rev.| Neurosci. 5, 1. https://doi.org/10.1038/nrn1517

Korzhevskii, D.E., Kirik, O. V., 2016. Brain Microglia and Microglial Markers. Neurosci. Behav. Physiol. 46, 284-290. https://doi.org/10.1007/s11055-016-0231-z

Kovats, S., 2015. Estrogen receptors regulate innate immune cells and signaling pathways. Cell. Immunol. https://doi.org/10.1016/j.cellimm.2015.01.018

Kreisel, T., Frank, M.G., Licht, T., Reshef, R., Ben-Menachem-Zidon, O., Baratta, M. V., Maier, S.F., Yirmiya, R., 2014. Dynamic microglial alterations underlie stress-induced depressive-like behavior and suppressed neurogenesis. Mol. Psychiatry 19, 699-709.

https://doi.org/10.1038/mp.2013.155

Kubera, M., Obuchowicz, E., Goehler, L., Brzeszcz, J., Maes, M., 2011. In animal models, psychosocial stress-induced (neuro)inflammation, apoptosis and reduced neurogenesis are associated to the onset of depression. Prog. Neuro-Psychopharmacology Biol. Psychiatry. https://doi.org/10.1016/j.pnpbp.2010.08.026

Levitan, R.D., Vaccarino, F.J., Brown, G.M., Kennedy, S.H., 2002. Low-dose dexamethasone challenge in women with atypical major depression: Pilot study. J. Psychiatry Neurosci.

Lewis, D.K., Johnson, A.B., Stohlgren, S., Harms, A., Sohrabji, F., 2008. Effects of estrogen receptor agonists on regulation of the inflammatory response in astrocytes from young adult and middleaged female rats. J. Neuroimmunol. https://doi.org/10.1016/j.jneuroim.2008.01.006

Li, C., Brake, W.G., Romeo, R.D., Dunlop, J.C., Gordon, M., Buzescu, R., Magarinos, A.M., Allen, 
P.B., Greengard, P., Luine, V., McEwen, B.S., 2004. Estrogen alters hippocampal dendritic spine shape and enhances synaptic protein immunoreactivity and spatial memory in female mice. Proc.

Natl. Acad. Sci. https://doi.org/10.1073/pnas.0307313101

Li, L.H., Wang, Z.C., Yu, J., Zhang, Y.Q., 2014. Ovariectomy results in variable changes in nociception, mood and depression in adult female rats. PLoS One.

https://doi.org/10.1371/journal.pone.0094312

Lind, D., Franken, S., Kappler, J., Jankowski, J., Schilling, K., 2005. Characterization of the neuronal marker NeuN as a multiply phosphorylated antigen with discrete subcellular localization. J.

Neurosci. Res. https://doi.org/10.1002/jnr.20354

Liu, Y., Chun-Man Ho, R., Mak, A., 2012. Interleukin (IL)-6, tumour necrosis factor alpha (TNF- $\alpha$ ) and soluble interleukin-2 receptors (sIL-2R) are elevated in patients with major depressive disorder: A meta-analysis and meta-regression. https://doi.org/10.1016/j.jad.2011.08.003

Lorsch, Z.S., Loh, Y.H.E., Purushothaman, I., Walker, D.M., Parise, E.M., Salery, M., Cahill, M.E., Hodes, G.E., Pfau, M.L., Kronman, H., Hamilton, P.J., Issler, O., Labonté, B., Symonds, A.E., Zucker, M., Zhang, T.Y., Meaney, M.J., Russo, S.J., Shen, L., Bagot, R.C., Nestler, E.J., 2018. Estrogen receptor $\alpha$ drives pro-resilient transcription in mouse models of depression. Nat. Commun. https://doi.org/10.1038/s41467-018-03567-4

Mahmoud, Rand, Wainwright, S.R., Chaiton, J.A., Lieblich, S.E., Galea, L.A.M., 2016a. Ovarian hormones, but not fluoxetine, impart resilience within a chronic unpredictable stress model in middle-aged female rats. Neuropharmacology 107, 278-293.

https://doi.org/10.1016/j.neuropharm.2016.01.033

Mahmoud, R., Wainwright, S.R., Chaiton, J.A., Lieblich, S.E., Galea, L.A.M., 2016. Ovarian hormones, but not fluoxetine, impart resilience within a chronic unpredictable stress model in middle-aged female rats. Neuropharmacology 107. https://doi.org/10.1016/j.neuropharm.2016.01.033

Mahmoud, Rand, Wainwright, S.R., Galea, L.A.M., 2016b. Sex hormones and adult hippocampal neurogenesis: Regulation, implications, and potential mechanisms. Front. Neuroendocrinol. 41, 129-152. https://doi.org/10.1016/j.yfrne.2016.03.002

Marcus, S.M., Kerber, K.B., Rush, A.J., Wisniewski, S.R., Nierenberg, A., Balasubramani, G.K., Ritz, L., Kornstein, S., Young, E.A., Trivedi, M.H., 2008. Sex differences in depression symptoms in 
treatment-seeking adults: confirmatory analyses from the Sequenced Treatment Alternatives to Relieve Depression study. Compr. Psychiatry 49, 238-246.

https://doi.org/10.1016/j.comppsych.2007.06.012

Mazzucco, C.A., Lieblich, S.E., Bingham, B.I., Williamson, M.A., Viau, V., Galea, L.A.M., 2006.

Both estrogen receptor $\alpha$ and estrogen receptor $\beta$ agonists enhance cell proliferation in the dentate gyrus of adult female rats. Neuroscience 141, 1793-1800.

https://doi.org/10.1016/j.neuroscience.2006.05.032

McClure, R.E.S., Barha, C.K., Galea, L.A.M., 2013. 17- $\beta$ Estradiol, but not estrone, increases the survival and activation of new neurons in the hippocampus in response to spatial memory in adult female rats. Horm. Behav. 63, 144-157. https://doi.org/10.1016/j.yhbeh.2012.09.011

McEwen, B.S., 2013. The Brain on Stress: Toward an Integrative Approach to Brain, Body, and Behavior. Perspect. Psychol. Sci. https://doi.org/10.1177/1745691613506907

McEwen, B.S., Nasca, C., Gray, J.D., 2016. Stress Effects on Neuronal Structure: Hippocampus, Amygdala, and Prefrontal Cortex. Neuropsychopharmacology.

https://doi.org/10.1038/npp.2015.171

Meyers, M.J., Sun, J., Carlson, K.E., Marriner, G.A., Katzenellenbogen, B.S., Katzenellenbogen, J.A., 2001. Estrogen receptor- $\beta$ potency-selective ligands: Structure-activity relationship studies of diarylpropionitriles and their acetylene and polar analogues. J. Med. Chem. 44, 4230-4251. https://doi.org/10.1021/jm010254a

Meziane, H., Ouagazzal, A.M., Aubert, L., Wietrzych, M., Krezel, W., 2007. Estrous cycle effects on behavior of $\mathrm{C} 57 \mathrm{BL} / 6 \mathrm{~J}$ and $\mathrm{BALB} / \mathrm{cByJ}$ female mice: Implications for phenotyping strategies. Genes, Brain Behav. https://doi.org/10.1111/j.1601-183X.2006.00249.x

Miller, A.H., Raison, C.L., 2016. The role of inflammation in depression: From evolutionary imperative to modern treatment target. Nat. Rev. Immunol. https://doi.org/10.1038/nri.2015.5

Monteiro, S., Roque, S., de Sá-Calçada, D., Sousa, N., Correia-Neves, M., Cerqueira, J.J., 2015. An efficient chronic unpredictable stress protocol to induce stress-related responses in C57BL/6 mice. Front. Psychiatry. https://doi.org/10.3389/fpsyt.2015.00006

Moreno-Jiménez, E.P., Flor-García, M., Terreros-Roncal, J., Rábano, A., Cafini, F., Pallas-Bazarra, N., Ávila, J., Llorens-Martín, M., 2019. Adult hippocampal neurogenesis is abundant in neurologically healthy subjects and drops sharply in patients with Alzheimer's disease. Nat. Med. 
https://doi.org/10.1038/s41591-019-0375-9

Morgan, M.A., Pfaff, D.W., 2002. Estrogen's effects on activity, anxiety, and fear in two mouse strains. Behav. Brain Res. https://doi.org/10.1016/S0166-4328(01)00398-9

Morgan, M.A., Pfaff, D.W., 2001. Effects of estrogen on activity and fear-related behaviors in mice. Horm. Behav. https://doi.org/10.1006/hbeh.2001.1716

Olsen, N.J., Kovacs, W.J., 1996. Gonadal steroids and immunity. Endocr. Rev. https://doi.org/10.1210/er.17.4.369

Ormerod, B.K., Galea, L.A.M., 2001. Reproductive status influences cell proliferation and cell survival in the dentate gyrus of adult female meadow voles: A possible regulatory role for estradiol. Neuroscience. https://doi.org/10.1016/S0306-4522(00)00474-7

Oyola, M.G., Handa, R.J., 2017. Hypothalamic-pituitary-adrenal and hypothalamic-pituitary-gonadal axes: sex differences in regulation of stress responsivity. Stress.

https://doi.org/10.1080/10253890.2017.1369523

Pacheco, A., Aguayo, F.I., Aliaga, E., Muñoz, M., García-Rojo, G., Olave, F.A., Parra-Fiedler, N.A., García-Pérez, A., Tejos-Bravo, M., Rojas, P.S., Parra, C.S., Fiedler, J.L., 2017. Chronic Stress Triggers Expression of Immediate Early Genes and Differentially Affects the Expression of AMPA and NMDA Subunits in Dorsal and Ventral Hippocampus of Rats. Front. Mol. Neurosci. https://doi.org/10.3389/fnmol.2017.00244

Padilla-Coreano, N., Bolkan, S.S., Pierce, G.M., Blackman, D.R., Hardin, W.D., Garcia-Garcia, A.L., Spellman, T.J., Gordon, J.A., 2016. Direct Ventral Hippocampal-Prefrontal Input Is Required for Anxiety-Related Neural Activity and Behavior. Neuron. https://doi.org/10.1016/j.neuron.2016.01.011

Pan, Y.-W., Chan, G.C.K., Kuo, C.T., Storm, D.R., Xia, Z., 2012. Inhibition of Adult Neurogenesis by Inducible and Targeted Deletion of ERK5 Mitogen-Activated Protein Kinase Specifically in Adult Neurogenic Regions Impairs Contextual Fear Extinction and Remote Fear Memory. J. Neurosci. https://doi.org/10.1523/jneurosci.6076-11.2012

Pothion, S., Bizot, J.C., Trovero, F., Belzung, C., 2004. Strain differences in sucrose preference and in the consequences of unpredictable chronic mild stress. Behav. Brain Res. https://doi.org/10.1016/j.bbr.2004.04.008

Ringner, M., 2008. What is principle component analysis? Nat. Biotechnol. 
Rocha, B.A., Fleischer, R., Schaeffer, J.M., Rohrer, S.P., Hickey, G.J., 2005. 17ß-Estradiol-induced antidepressant-like effect in the Forced Swim Test is absent in estrogen receptor- $\beta$ knockout (BERKO) mice. Psychopharmacology (Berl). https://doi.org/10.1007/s00213-004-2078-1

Roy, A., Linnoila, M., Jimerson, D.C., Gold, P., Pickar, D., 1986. Pre-menopausal and postmenopausal depressed women. Australas. Psychiatry. https://doi.org/10.3109/00048678609158899

Saijo, K., Collier, J.G., Li, A.C., Katzenellenbogen, J.A., Glass, C.K., 2011. An ADIOL-ER $\beta$-CtBP transrepression pathway negatively regulates microglia-mediated inflammation. Cell. https://doi.org/10.1016/j.cell.2011.03.050

Salk, R.H., Hyde, J.S., Abramson, L.Y., 2017. Gender differences in depression in representative national samples: Meta-analyses of diagnoses and symptoms. Psychol. Bull. 143, 783-822. https://doi.org/10.1037/bul0000102

Samuels, B.A., Hen, R., 2011. Novelty-suppressed feeding in the mouse. Neuromethods. https://doi.org/10.1007/978-1-61779-313-4_7

Santarelli, L., Saxe, M., Gross, C., Surget, A., Battaglia, F., Dulawa, S., Weisstaub, N., Lee, J., Duman, R., Arancio, O., Belzung, C., Hen, R., 2003. Requirement of hippocampal neurogenesis for the behavioral effects of antidepressants. Science 301, 805-9. https://doi.org/10.1126/science.1083328

Schoenfeld, T.J., Gould, E., 2012. Stress, stress hormones, and adult neurogenesis. Exp. Neurol. https://doi.org/10.1016/j.expneurol.2011.01.008

Serova, L.I., Harris, H.A., Maharjan, S., Sabban, E.L., 2010. Modulation of responses to stress by estradiol benzoate and selective estrogen receptor agonists. J. Endocrinol. https://doi.org/10.1677/JOE-10-0029

Setiawan, E., Attwells, S., Wilson, A.A., Mizrahi, R., Rusjan, P.M., Miler, L., Xu, C., Sharma, S., Kish, S., Houle, S., Meyer, J.H., 2018. Association of translocator protein total distribution volume with duration of untreated major depressive disorder: a cross-sectional study 339 . https://doi.org/10.1016/S2215-0366(18)30048-8

Setiawan, E., Wilson, A.A., Mizrahi, R., Rusjan, P.M., Miler, L., Rajkowska, G., Suridjan, I., Kennedy, J.L., Rekkas, P.V., Houle, S., Meyer, J.H., 2015. Role of translocator protein density, a marker of neuroinflammation, in the brain during major depressive episodes. JAMA Psychiatry 72, 268-275. 
https://doi.org/10.1001/jamapsychiatry.2014.2427

Smith, J.A., Das, A., Butler, J.T., Ray, S.K., Banik, N.L., 2011. Estrogen or estrogen receptor agonist inhibits lipopolysaccharide induced microglial activation and death. Neurochem. Res. https://doi.org/10.1007/s11064-010-0336-7

Soares, C.N., 2014. Mood disorders in midlife women: Understanding the critical window and its clinical implications. Menopause. https://doi.org/10.1097/GME.0000000000000193

Srivastava, D.P., Penzes, P., 2011. Rapid estradiol modulation of neuronal connectivity and its implications for disease. Front. Endocrinol. (Lausanne). https://doi.org/10.3389/fendo.2011.00077

Stauffer, S.R., Coletta, C.J., Tedesco, R., Nishiguchi, G., Carlson, K., Sun, J., Katzenellenbogen, B.S., Katzenellenbogen, J. a, 2000. Pyrazole ligands: structure-affinity/activity relationships and estrogen receptor-alpha-selective agonists. J. Med. Chem. 43, 4934-4947.

https://doi.org/jm000170m [pii]

Stedenfeld, K.A., Clinton, S.M., Kerman, I.A., Akil, H., Watson, S.J., Sved, A.F., 2011. Noveltyseeking behavior predicts vulnerability in a rodent model of depression. Physiol. Behav. https://doi.org/10.1016/j.physbeh.2011.02.001

Stetler, C., Miller, G.E., 2011. Depression and hypothalamic-pituitary-adrenal activation: A quantitative summary of four decades of research. Psychosom. Med. https://doi.org/10.1097/PSY.0b013e31820ad12b

Strange, B.A., Witter, M.P., Lein, E.S., Moser, E.I., 2014. Functional organization of the hippocampal longitudinal axis. Nat. Rev. Neurosci. https://doi.org/10.1038/nrn3785

Surget, A., Tanti, A., Leonardo, E.D., Laugeray, A., Rainer, Q., Touma, C., Palme, R., Griebel, G., Ibarguen-Vargas, Y., Hen, R., Belzung, C., 2011. Antidepressants recruit new neurons to improve stress response regulation. Mol. Psychiatry 16, 1177-1188. https://doi.org/10.1038/mp.2011.48

Tanapat, P., Hastings, N.B., Gould, E., 2005. Ovarian steroids influence cell proliferation in the dentate gyrus of the adult female rat in a dose- and time-dependent manner. J. Comp. Neurol. https://doi.org/10.1002/cne.20385

Tanapat, P., Hastings, N.B., Reeves, A.J., Gould, E., 1999. Estrogen stimulates a transient increase in the number of new neurons in the dentate gyrus of the adult female rat. J. Neurosci. 19, 5792-801. https://doi.org/10.1016/j.brainresrev.2007.06.011

Tobin, M.K., Musaraca, K., Disouky, A., Shetti, A., Bheri, A., Honer, W.G., Kim, N., Dawe, R.J., 
Bennett, D.A., Arfanakis, K., Lazarov, O., 2019. Human Hippocampal Neurogenesis Persists in Aged Adults and Alzheimer's Disease Patients. Cell Stem Cell.

https://doi.org/10.1016/j.stem.2019.05.003

Vegeto, E., Benedusi, V., Maggi, A., 2008. Estrogen anti-inflammatory activity in brain: A therapeutic opportunity for menopause and neurodegenerative diseases. Front. Neuroendocrinol.

https://doi.org/10.1016/j.yfrne.2008.04.001

Vegeto, E., Bonincontro, C., Pollio, G., Sala, a, Viappiani, S., Nardi, F., Brusadelli, a, Viviani, B., Ciana, P., Maggi, a, 2001. Estrogen prevents the lipopolysaccharide-induced inflammatory response in microglia. J. Neurosci. 21, 1809-1818. https://doi.org/21/6/1809 [pii]

Wainwright, S.R., Barha, C.K., Hamson, D.K., Epp, J.R., Chow, C., Lieblich, S.E., Rutishauser, U., Galea, L.A.M., 2016. Enzymatic depletion of the polysialic acid moiety associated with the neural cell adhesion molecule inhibits antidepressant efficacy. Neuropsychopharmacology 41, 16701680. https://doi.org/10.1038/npp.2015.337

Walf, A.A., Frye, C.A., 2010. Estradiol reduces anxiety- and depression-like behavior of aged female mice. Physiol. Behav. https://doi.org/10.1016/j.physbeh.2009.09.017

Walf, A.A., Frye, C.A., 2005. ER $\beta$-selective estrogen receptor modulators produce antianxiety behavior when administered systemically to ovariectomized rats. Neuropsychopharmacology. https://doi.org/10.1038/sj.npp.1300713

Walf, A.A., Koonce, C., Manley, K., Frye, C.A., 2009a. Proestrous compared to diestrous wildtype, but not estrogen receptor beta knockout, mice have better performance in the spontaneous alternation and object recognition tasks and reduced anxiety-like behavior in the elevated plus and mirror maze. Behav. Brain Res. 196, 254-260. https://doi.org/10.1016/j.bbr.2008.09.016

Walf, A.A., Koonce, C.J., Frye, C.A., 2008. Estradiol or diarylpropionitrile administration to wild type, but not estrogen receptor beta knockout, mice enhances performance in the object recognition and object placement tasks. Neurobiol. Learn. Mem. 89, 513-521.

https://doi.org/10.1016/j.nlm.2008.01.008

Walf, A.A., Paris, J.J., Frye, C.A., 2009b. Chronic estradiol replacement to aged female rats reduces anxiety-like and depression-like behavior and enhances cognitive performance.

Psychoneuroendocrinology. https://doi.org/10.1016/j.psyneuen.2009.01.004

Walf, A.A., Rhodes, M.E., Frye, C.A., 2004. Antidepressant effects of ER $\beta$-selective estrogen receptor 
modulators in the forced swim test, in: Pharmacology Biochemistry and Behavior. https://doi.org/10.1016/j.pbb.2004.03.023

Wang, A.K., Miller, B.J., 2018. Meta-analysis of Cerebrospinal Fluid Cytokine and Tryptophan Catabolite Alterations in Psychiatric Patients: Comparisons between Schizophrenia, Bipolar Disorder, and Depression. Schizophr. Bull. https://doi.org/10.1093/schbul/sbx035

Waters, E.M., Mitterling, K., Spencer, J.L., Mazid, S., McEwen, B.S., Milner, T.A., 2009. Estrogen receptor alpha and beta specific agonists regulate expression of synaptic proteins in rat hippocampus. Brain Res. https://doi.org/10.1016/j.brainres.2009.06.090

Weiser, M.J., Foradori, C.D., Handa, R.J., 2010. Estrogen receptor beta activation prevents glucocorticoid receptor-dependent effects of the central nucleus of the amygdala on behavior and neuroendocrine function. Brain Res. https://doi.org/10.1016/j.brainres.2010.03.098

Weiser, M.J., Handa, R.J., 2009. Estrogen impairs glucocorticoid dependent negative feedback on the hypothalamic-pituitary-adrenal axis via estrogen receptor alpha within the hypothalamus. Neuroscience. https://doi.org/10.1016/j.neuroscience.2008.12.058

Weiser, M.J., Wu, T.J., Handa, R.J., 2009. Estrogen receptor- $\beta$ agonist diarylpropionitrile: Biological activities of R- And S-enantiomers on behavior and hormonal response to stress. Endocrinology. https://doi.org/10.1210/en.2008-1355

Wells, A.M., Ridener, E., Bourbonais, C.A., Kim, W., Pantazopoulos, H., Carroll, F.I., Kim, K.S., Cohen, B.M., Carlezon, W.A., 2017. Effects of chronic social defeat stress on sleep and circadian rhythms are mitigated by kappa-opioid receptor antagonism. J. Neurosci. 37, 7656-7668. https://doi.org/10.1523/JNEUROSCI.0885-17.2017

Willner, P., 2017. The chronic mild stress (CMS) model of depression: History, evaluation and usage. Neurobiol. Stress. https://doi.org/10.1016/j.ynstr.2016.08.002

Woolley, C.S., Gould, E., Frankfurt, M., McEwen, B.S., 1990. Naturally occurring fluctuation in dendritic spine density on adult hippocampal pyramidal neurons. J. Neurosci.

Workman, J.L., Chan, M.Y.T., Galea, L.A.M., 2015. Prior high corticosterone exposure reduces activation of immature neurons in the ventral hippocampus in response to spatial and nonspatial memory. Hippocampus 25, 329-344. https://doi.org/10.1002/hipo.22375

Yang, F., Tao, J., Xu, L., Zhao, N., Chen, J., Chen, W., Zhu, Y., Qiu, J., 2014. Estradiol decreases rat depressive behavior by estrogen receptor beta but not alpha: no correlation with plasma 
corticosterone. Neuroreport 25, 100-4. https://doi.org/10.1097/WNR.0000000000000052

Yehuda, R., Southwick, S.M., Krystal, J.H., Bremner, D., Charney, D.S., Mason, J.W., 1993. Enhanced suppression of cortisol following dexamethasone administration in posttraumatic stress disorder.

Am. J. Psychiatry. https://doi.org/10.1176/ajp.150.1.83

Young, E.A., Kotun, J., Haskett, R.F., Grunhaus, L., Greden, J.F., Watson, S.J., Akil, H., 1993. Dissociation between Pituitary and Adrenal Suppression to Dexamethasone in Depression. Arch. Gen. Psychiatry. https://doi.org/10.1001/archpsyc.1993.01820170073010 